\title{
LA POLITICA EXTERIOR DE VENEZUELA Y SUS OPCIONES EN EL MARCO DE LOS CAMBIOS GLOBALES Y REGIONALES
}

\author{
Andrés Serbin
}

\begin{abstract}
Las transformaciones en el sistema internacional han provocado distintas reacciones a nivel hemisférico. Pero, en general, se aprecia que los países se han orientado a profundizar la apertura económica mediante acuerdos de libre comercio y los esquemas de integración. La Cuenca del Caribe no ha estado ajena a estos procesos y, particularmente Venezuela, ha impulsado importantes cambios, reformulando su política exterior e iniciando la etapa del "gran viraje". Así, se pretende lograr una activa inserción económica internacional, complementando las exportaciones petroleras con la oferta de productos no tradicionales en un marco subregional. Tomando en cuenta la prioridad dada a los temas subregionales, el autor se refiere a las relaciones con Estados Unidos, Colombia, Pacto Andino, Grupo de los Tres, y el Caribe y Centroamérica. Finalmente, al evaluar los resultados de esta tendencia, concluye que si bien ha habido grandes logros, el costo ha sido la desvinculación política y económica en el ámbito global.
\end{abstract}

\section{1.- El marco de las transformaciones globales y las reaccio- nes hemisféricas.}

En el último lustro, el sistema internacional ha sufrido una serie de transformaciones significativas. Por un lado, en el plano estratégicomilitar e ideológico, los cambios iniciados por la perestroika en la Unión Soviética y sus repercusiones en toda Europa Oriental, han dado lugar al fin de la Guerra Fría y a la desaparición de la bipolaridad estratégica que caracterizó al sistema internacional en las cuatro décadas precedentes. Por otro lado, el proceso de creciente globalización e interdependencia económica se há articulado con un proceso de regionalización en torno a la emergencia de tres bloques de poder y de dinamismo económico a nivel mundial: la Comunidad Económica Europea, América del Norte, y Japón y sus socios asiáti- 
$\cos$, generando un sistema internacional caracterizado, en el plano económico, por la multipolaridad. ${ }^{1}$

Estas transformaciones han dado lugar a la conformación de un sistema internacional de carácter uni-multipolar ${ }^{2}$, con un actor hegemónico a nivel estratégico-militar -Estados Unidos-y tres focos de dinamismo económico en torno a los tres bloques mencionados. Pero asimismo, a partir del fin de la Guerra Fría, han provocado un cambio en los temas prioritarios de la agenda internacional, desplazando los aspectos de seguridad por los temas económicos globales que han emergido como componentes destacados de la nueva dinámica internacional (Buzan, 1990).

En este contexto global, las reacciones iniciales a nivel hemisférico han seguido lineamientos distintivos en el Norte y en el Sur del continente americano, en el marco general de una creciente tendencia a la regionalización (Hurrell, 1992).

Por un lado, Estados Unidos ha consolidado su posición como actor hegemónico en el plano de la seguridad mundial, pese a que, a su vez, en el plano económico ha sido afectado por problemas de déficit fiscal y de deuda externa, como así también por una recesión económica y por la progresiva pérdida de su hegemonía financiera en el sistema internacional. En este marco y en función de necesidades económicas y estratégicas de los Estados Unidos (SELA, 1991a), la administración del Presidente Bush dio, en junio de 1990, un nuevo sesgo a las relaciones interamericanas, impulsando la creación de un área de libre comercio entre Canadá, Estados Unidos y México (ALCAN, en su sigla en español y NAFTA, en inglés), al proponer la ampliación del acuerdo de libre comercio entre los dos primeros países a México, y al anunciar, poco después, el lanzamiento de una Iniciativa para las Américas tendiente a la creación futura de una zona de libre comercio hemisférica (Tulchin, 1992).

Por otra parte, los países de América Latina y el Caribe han reaccionado frente a los cambios globales expresando inicialmente su inquietud por su eventual marginación del sistema internacional, tanto por la pérdida de su importancia estratégica en el contexto de

\footnotetext{
${ }^{1}$ Es de senalar, de acuerdo a Weintraub, que en el contexto europeo y estadounidense, el término bloque se refiere fundamentalmente al establecimiento de acuerdos comerciales preferenciales entre un grupo de naciones, (Weintraub, 1991, p. 5).

2"Seen in this light, the world is now uni-multipolar, with one major pole of power but many" other important secondary actors that may even play primary roles on some issues, particularly global economic isoues", (Braveboy-Wagner, 1991).
} 
la Guerra Fría como por los efectos paralizadores, en términos de desarrollo y de crecimiento económico, que pudo implicar la crisis de la deuda externa y las secuelas de la llamada "década perdida para la región, y sus efectos negativos sobre una inserción ventajosa en la nueva dinámica económica internacional. A su vez, el temor a la marginalización global, con la disminución consecuente del flujo de inversiones y de intercambio comercial, se ha comenzado a articular con el fin de la tendencia a la introspección económica que caracterizó a América Latina en décadas precedentes; con el reconocimiento de la renovada importancia económica de Estados Unidos para la región y con un nuevo afán integracionista (Hurrell, 1991, pp. 124128), que se han articulado, por otra parte, con la implementación de programas de ajuste y de reestructuración económica mayoritariamente promovidos en el entorno de procesos de redemocratización en la mayoría de los países latinoamericanos. En esta etapa de las reacciones de América Latina y el Caribe frente a la constitución de bloques económicos y comerciales y las transformaciones globales, el énfasis integracionista ha adquirido nuevas características en comparación con los esfuerzos previos y se ha articulado al desarrollo de los procesos de ajuste estructural de la región como reacción a la crisis económica desatada por la deuda externa en la década del ochenta. ${ }^{3}$

Estas reacciones distintivas (y que es necesario matizar en cada caso y cada país) dan pie para respuestas diferenciadas a nivel hemisférico. Todas, sin embargo, básicamente giran en torno a la necesidad de profundizar en los procesos de apertura y liberalización comercial a través de la implementación de diversos acuerdos de libre comercio y de la aceleración de los esquemas de integración económica subregional previamente iniciados o recientemente creados. Asimismo, todas ellas presuponen la necesidad de ampliar y profundizar los mecanismos de la economía de mercado y de impulsar programas de ajuste económico que ponen en cuestión las estrategias tradicionales de desarrollo promovidas en décadas anteriores y asociadas a la "sustitución de las importaciones" (CEPAL, 1991b). Por otra parte, el énfasis en la apertura comercial y en un crecimiento económico

\footnotetext{
${ }^{3}$ Como señala un reciente documento del SELA: "La etapa de ajuste económico tendiente a generar el superávit comercial externo que permitiera financiar las transferencias para servir al endeudamiento externo con bancos y organizaciones extraregionales (1982-1988) era incompatible con el cumplimiento y la profundización de las metas originales en los programas de integración. Transitada esta primera etapa de ajuste, algunos cambios en la orientación global de la política económica fayorecen el relànzamiento de los programas de liberalización económica a escala regional" (SELA, 1991b, p. 3).
} 
basado en las exportaciones apunta no sólo a ampliar los espacios económicos regionales en busca de ventajas competitivas y mercados más extensos sino también a insertarse más ventajosamente en el sistema internacional.

En suma, frente a la globalización de la economía mundial y a la regionalización actual en torno a los tres bloques de mayor dinamismo económico y a sus interrelaciones, los Estados de América Latina y el Caribe han reaccionado promoviendo la regionalización focalizada en núcleos regionales, "con el apoyo de acuerdos que refuerzan los vínculos privilegiados entre Estados que comparten un ámbito geográfico, histórico, cultural o económico" (CEPAL, 1991 b, p. 4).

En América Latina y el Caribe, este proceso de regionalización, acelerado en los últimos años, pese a asociarse fundamentalmente con procesos de apertura comercial tendientes a reforzar el comercio subregional y bilateral, ha estado estrechamente imbricado a modalidades de coordinación y de concertación política, en tanto, con frecuencia, los factores económicos han sido insuficientes para fundamentar la emergencia de bloques regionales y, en general, ésta ha estado asociada a elementos políticos, geopolíticos y culturales. En este sentido, es necesario tener en cuenta que, con frecuencia, la regionalización ha estado signada por percepciones y actitudes definidas frente a la cooperación hemisférica y a las relaciones con Estados Unidos y con otros países industrializados extrahemisféricos, en particular a raíz del impulso del ALCAN y del lanzamiento de la Iniciativa para las Américas. ${ }^{4}$

Sin embargo, al margen de las consideraciones políticas y geopolíticas, el patrón común de la tendencia actual a acelerar los procesos de cooperación y de integración subregional, se ha basado en la promoción de la liberalización comercial a nivel bilateral o plurilateral, desplazando con frecuencia a un segundo plano las consideraciones tradicionales acerca de la necesidad de armonizar la integración productiva y tecnológica y de coordinar las políticas macroeconómicas, temas que recién comienzan a reemerger en la agenda regional (SELA, 1991b; CEPAL, 1992c).

\footnotetext{
${ }^{4}$ Por regionalismo Hurrell entiende "a set of policies by one or more states designed to promote the emergence of a cohesive regional unit, which dominates the pattern of relations between the states of that region and the rest of the world, and which forms the organizing basis for policy within the region acrass a range of issues" (Hurrell1, 1992, p. 123).
} 


\section{2.- La Cuenca del Caribe en la década del noventa: el marco subregional.}

La Cuenca del Caribe ha estado particularmente sensible a estos procesos, en tanto, a raíz del fin de la Guerra Fría y del dinamismo económico global, su importancia estratégica ha disminuido significativamente, provocando un gradual desentendimiento de los actores extrarregionales que tradicionalmente se han involucrado en la región. Por un lado, no obstante los efectos inerciales del antagonismo entre Estados Unidos y el Gobierno de Fidel Castro, Cuba se ha visto crecientemente aislada en el Caribe y concentrada en sus propios problemas económicos a raíz de la ruptura y dilución de sus relaciones con Europa Oriental y la antigua Unión Soviética, al punto de que se ha desvanecido su potencial de amenaza para la región. Por otra parte, el proceso de pacificación en Centroamérica a partir de los acuerdos de Esquipulas, ha contribuido a una distensión regional y a la reemergencia de acuerdos de cooperación y de integración subregional a través de la repotenciación de la SIECA (Secretaría de Integración Económica Centroamericana). Finalmente, los Estados del Caribe insular se han concentrado crecientemente en los factores internos de desestabilización (como los ilustrados por el frustrado intento de golpe de los fundamentalistas islámicos en Trinidad en junio de 1990) y en promover y acelerar el proceso de integración iniciado en el marco del Mercado Común del Caribe (CARICOM), a la cual a su vez intentan vincularse crecientemente República Dominicana, Haití (actualmente estigmatizada y aislada en el hemisferio a raíz del derrocamiento del Gobierno democrático de Aristide) y Surinam (Serbin, 1989; 1990; 1991a; 1992a).

Como consecuencia, desde el punto de vista estratégico y geopolítico, la agenda de seguridad del Caribe ha virado de las prioridades asignadas a la contención de la influencia cubano-soviética propias de la Guerra Fría, el énfasis en los problemas de control de narcotráfico, los flujos migratorios hacia el Norte y la seguridad ambiental en la percepción de los actores extrarregionales como Estados Unidos y los países europeos con anclajes coloniales en el Caribe (Serbin; 1991b; 1992b; Griffith; 1991). Sin embargo, para los Estados de la región, las nuevas preocupaciones de seguridad giran crecientemente en torno a su vulnerabilidad económica, a la necesidad de formular una nueva estrategia de desarrollo articulada a las presiones de los cambios globales, los efectos de una inserción des- 
ventajosa en la economía internacional y a las secuelas que pueda acarrear, en términos de los acuerdos preferenciales y no recíprocos como la Iniciativa de la Cuenca del Caribe, las convenciones de Lomé o el programa Caribean, la emergencia del ALCAN y la unificación europea (Serbin, 1991 y y c).

En función de estas preocupaciones se han acelerado los procesos de integración promovidos por esquemas como el Mercado Común Centroamericano o la CARICOM. Simultáneamente, frente al vacío geopolítico generado en la Cuenca del Caribe, las potencias regionales medias han promovido el establecimiento de un Acuerdo de Libre Comercio a través del Grupo de los Tres (G-3: Colombia, México y Venezuela) con un fuerte énfasis en la cooperación con Centroamérica y el Caribe insular. Esta iniciativa ha encontrado un eco positivo por parte de los Estados más pequeños de la Cuenca del Caribe, tanto en términos de promover una relación más estrecha entre Centroamérica y el Caribe como de ampliar la concepción de la región al conjunto de la Cuenca del Caribe, incluyendo a dichas potencias medias, en el marco de una Asociación de Estados del Caribe (WrC, 1992; Serbin, 1992c y 1993).

Este cambio significativo en la atmósfera regional responde a varias razones. For un lado, a la necesidad de establecer alianzas y vínculos más estrechos a nivel regional para potenciar una presencia caribeña y una mayor capacidad de negociación en los foros multilaterales. Por otro, a la necesidad de profundizar en los procesos de cooperación e integración subregional con el propósito de ampliar los espacios económicos existentes y potenciar una inserción más eficiente y competitiva en el sistema económico internacional en el marco de las nuevas estrategias de crecimiento económico basadas en la promoción de exportaciones. Asimismo, estos objetivos económicos, se articulan, en general, con un conjunto de políticas estatales orientadas a profundizar y consolidar los procesos de democratización y a afirmar la estabilidad política regional.

Esta dinámica ha generado una intensificación de las actividades e iniciativas diplomáticas subregionales (como lo revelan la participación de los países centroamericanos y de la CARICOM en el Grupo de Río, el involucramiento más activo de éstos últimos en la Organización de Estados Americanos o la convergencia de los países anglófonos e hispanoparlantes en la búsqueda de una salida a la crisis haitiana); una profundización de los esquemas de integración existentes y el impulso a nuevos acuerdos de libre comercio entre los 
principales protagonistas regionales (como se evidencia de los casos de CARICOM, SIECA o el G-3, y la articulación de diversos acuerdos de libre comercio entre este último grupo y los países de la CARICOM y Centroamérica); y una creciente focalización subregional, en tanto el Pacto Andino tropieza con dificultades y el Cono Sur se concentra en los avances del MERCOSUR.

En este marco general, un caso particular a nivel hemisférico y subregional está constituido por la experiencia reciente de Venezuela, condicionada tanto por presiones externas como por condicionamientos regionales e internos, para impulsar una serie de reformas y un cambio significativo en su política exterior, bajo el rubro genérico del "gran viraje".

\section{3.- Presión externa y crisis doméstica: el "gran viraje" y la política exterior de Venezuela.}

Venezuela se ha distinguido en el ámbito internacional, tanto global como hemisférico y subregional, por la combinación de la existencia y consolidación de un sistema democrático estable a lo largo de más de tres décadas, y por la explotación de sus recursos petroleros como un ingrediente fundamental tanto de una economía rentista como de una proyección internacional frecuentemente sobredimensionada (Serbin, 1993b).

Este cuadro sufrió una serie de transformaciones cruciales en la década del ochenta. El efecto combinado de la baja de los precios del petróleo en el mercado internacional y el impacto del endeudamiento externo provocaron una crisis económica sin precedentes en el país, con una serie de secuelas sociales y políticas que pusieron bajo signo de interrogación la alegada estabilidad del sistema democrático venezolano (Serbin, 1993c; Tulchin, 1993).

Hacia 1988, desequilibrios externos, dificultades en el área fiscal, desajustes en la esfera monetaria y la reticencia de la banca internacional para otorgar préstamos, conformaron una serie de condiciones negativas que se combinaron con la merma de los ingresos petroleros y la presión de la deuda. En este marco, la proximidad de las elecciones presidenciales de 1988 dio lugar al mantenimiento de una política fiscal expansiva provocando una caída de las reservas internacionales (Ortiz, 1992b, pp. 40-41). 
Sin embargo, una nueva etapa se abre en 1989 al asumir la presidencia por segunda vez Carlos Andrés Pérez. Esta etapa, signada por una gran reacción a nivel gubernamental calificada como el "gran viraje", se enmarca tanto en las necesidades de reorientar la política económica del país a raíz del impacto de la crisis económica y de readecuar el sistema político a esta reorientación, cómo en la urgencia de redimensionar la política exterior del mismo frente a los desafios impuestos por las transformaciones globales y hemisféricas en curso. La articulación de estas transformaciones en el marco internacional y en el marco hemisférico con los síntomas de agotamiento del modelo económico basado en la renta petrolera en Venezuela condujeron, en 1989, al inicio del proceso de reestructuración económica siguiendo los lineamientos de un programa de ajuste macroeconómico ortodoxo basado en una combinación de ajustes restrictivos fiscales y monetarios (Ortiz, 1992b, p. 41).

En consecuencia, esta fase de la evolución del sistema venezolano se caracterizó, en lo interno, por una serie de iniciativas radicales, especialmente en el plano económico, que intentan promover un programa drástico de reestructuración, a través de la implementación de medidas tendientes a la reducción del gasto público, a la eliminación de los subsidios directos e indirectos del Estado, el aumento del precio de la gasolina y de los servicios, a la desregulación, a la privatización, a la reconversión industrial y a la reducción de los derechos de aduana con el propósito de reducir el déficit fiscal, liberalizar los intercambios y las tasas de interés, controlar tos precios y abrir la economía al comercio y a la competencia internacional. Este programa radical se articula con una estrategia de desarrollo crecientemente basada en la promoción del crecimiento hacia afuera y la apertura comercial, que intentan marcar un viraje fundamental en la economía y en la política del país y que acarrean una serie de consecuencias y de costos políticos y sociales significativos (Toro Hardy, J., 1992; Fundafuturo, 1992).

En el marco de estos cambios y de los costos sociales y políticos consiguientes, signados por una radical reacción de diversos sectores de la población que dan lugar tanto al "caracazo" de febrero de 1989, poco después de asumir la presidencia Carlos Andrés Pérez, como a los frustrados intentos de golpe militar del 4 de febrero de 1992 (Sonntag, 1992; Serbin, 1992d) y del 27 de noviembre, en esta etapa se decantan nuevas prioridades en la política exterior de Venezuela. Estas prioridades responden a las interrogantes abiertas por las 
características que deberá asumir la nueva inserción internacional del país en el contexto de la disminución de la importancia mundial del petróleo, a raíz del desequilibrio del sector externo, signado por la contracción de los precios de los hidrocarburos, el alto servicio de la deuda y la debilidad de las exportaciones no tradicionales (Ortiz, 1992b, p. 43; Serbin, 1993b). Consecuentemente, se intenta desplegar una diplomacia comercial más activa orientada a incrementar las exportaciones del país y a vincularse con espacios económicos ampliados a través de acuerdos de libre comercio y de la aceleración de los procesos de integración subregional (Rojas, 1992).

Es así que el VIII Plan de la Nación perfila claramente los elementos de la estrategia de desarrollo propuesta para lograr una inserción más ventajosa de Venezuela en el sistema internacional, sobre la base de: a) una agresiva inserción en el escenario mundial; b) una política exterior como apoyo a los objetivos de apertura económica dentro del contexto de la defensa de los principios del libre comercio, la integración latinoamericana y el fortalecimiento de la solidaridad democrática internacional; c) un nuevo enfoque de la integración regional, fortaleciendo las instituciones de cooperación e integración, propiciando acuerdos de apertura comercial y de coordinación de políticas macroeconómicas, y propiciando alianzas estratégicas en diversos ámbitos (tecnológicas, culturales y políticas); d) una diplomacia comercial agresiva en lo bilateral y en lo multilateral, para apoyar el incremento de las exportaciones venezolanas, y e) el ingreso al GATT y el establecimiento de canales efectivos de comunicación entre Venezuela y las instituciones internacionales de cooperación e integración (Cordiplan, 1990; cit. en Cardozo, 1992a, p. 5).

En función de estos objetivos se intenta desarrollar una política comercial basada en tres pilares: la apertura gradual de la economía venezolana destinada a promover una mayor eficiencia y competitividad de la industria y la agricultura del país; una activa estrategia de integración y de negociaciones comerciales cuyo propósito es la ampliación de mercados y de oportunidades de comercio e inversión para los agentes locales; y una política integral de promoción de las exportaciones con especial énfasis en las exportaciones no tradicionales (Rodríguez M., M., 1993a).

Estos tres pilares de la política comercial se expresan en tres componentes altamente relevantes: la política arancelaria, la asociación o integración, y la promoción de exportaciones, en el marco del 
Decreto $N^{\circ} 239$ del 24 de mayo de 1989 que fundamenta la programación de la Nueva Política Comercial, como eje de esta iniciativa renovadora (Ortiz, 1992b, p. 15). En esta perspectiva, explícitamente, la Nueva Política Comercial se basa en: 1) una política de apertura comercial que busca romper el sesgo antiexportador y promover la transformación estructural del aparato productivo; 2) un replanteamiento de la integración económica que apunta a la coordinación de políticas macroeconómicas y a la liberación de barreras comerciales; y 3) una política de promoción de exportaciones, mediante la cual se trata de instaurar un marco macroeconómico que permita organizar la estructura productiva en función de los precios internacionales (Ortiz, 1992b, p. 126).

El primer pilar es el que presenta los mayores avances en los cuatro primeros años del Gobierno de Carlos Andrés Pérez, en tanto se introduce un programa radical de reducción arancelaria que se acelera durante el año 1992. Como señala el Presidente del Instituto de Comercio Exterior: "El contraste con la situación anterior es notable. En 1988, había aranceles que llegaban a 135 por ciento y ahora el tope máximo es de sólo 20 por ciento. El arancel promedio era de 34 por ciento y ahora es de 10 por ciento. Más importante aún, se han eliminado del régimen de importaciones todas las medidas no arancelarias, y con ellas la discrecionalidad de los funcionarios públicos que eran, en última instancia, quienes determinaban lo que podía ser adquirido por los venezolanos en el exterior" (Rodríguez, 1993a).

En cuanto al segundo pilar, se avanza rápidamente en la integración económica con Colombia, al punto de que el eje VenezuelaColombia (donde el intercambio comercial en el año 1992 casi ha alcanzado los 1.000 millones de dólares), se constituye en el más avanzado tanto del Pacto Andino como del Acuerdo de Libre Comercio promovido en el seno del Grupo de los Tres (México, Colombia y Venezuela). Asimismo, se acelera el proceso de integración del Pacto Andino no obstante la autoexclusión temporal del Perú y la creciente vinculación de Bolivia con el MERCOSUR; se inicia la discusión de los acuerdos de libre comercio con Chile y de los acuerdos no recíprocos con Centroamérica y la CARICOM, al punto que Venezuela se incorpora como observador a este organismo en 1991. Simultáneamente, en agosto de 1990, Venezuela se incorpora al GATT.

Finalmente, en lo que respecta al tercer pilar, se eliminan los bonos de exportación, se facilitan parcialmente algunos trámites para 
la exportación, se intenta introducir mecanismos de devolución de impuestos ("drawback"), se promueve la privatización de los puertos y se propone la creación de un Banco de Comercio Exterior. En esencia, esta política intenta impulsar la exportación de productos no tradicionales, tanto en el ámbito de la explotación de recursos naturales por parte de empresas del Estado (petroquímica, aluminio, carbón, gas y acero) (Zambrano, 1993) como, principalmente, en el ámbito de manufacturas y servicios por parte del sector privado, para lo cual se enfatiza el papel de este último en la exportación y en los procesos de integración subregional.

En suma, partiendo de un diagnóstico que pone en evidencia las amenazas y presiones existentes para el tradicional y principal rubro exportador del país -el petróleo y sus derivados-, la nueva estrategia de desarrollo promovida por el Gobierno de Carlos Andrés Pérez, enfatiza, por un lado, los pasos a seguir para maximizar la capacidad de sus ventajas competitivas en este campo, a la vez que, por otro, despliega una serie de medidas tendientes a la liberalización comercial, la integración y la apertura de espacios económicos ampliados con el fin de diversificar y potenciar la capacidad exportadora del país en los sectores no tradicionales. En este proceso, la política de regionalización, con su énfasis subregional, constituye un eje fundamental de la política exterior del "gran viraje", optimizando la experiencia de cooperación económica, concertación política y alianza geoestratégica desarrollada en etapas previas.

\section{4.- Logros, falencias y dificultades de la nueva política comercial: el nuevo rol del sector privado y las expor- taciones no tradicionales.}

Es de subrayar que pese a que "ninguna otra industria pueda hoy generar los ingresos netos como lo hace el petróleo y sus derivados" (Zambrano, 1992, p. 9), se ha hecho un esfuerzo significativo para complementar y ampliar la oferta exportadora del país a través de las exportaciones no tradicionales. Estas incluyen, por un lago, una amplia gama de productos basados en la explotación estatal de recursos minerales sobre la base del aprovechamiento de los ingentes recursos energéticos del país, tales como la industria del aluminio y el acero, y también la petroquímica y la producción de carbón y de 
gas natural, y por otro, un conjunto donde predominan las manufacturas, básicamente a cargo del sector privado (Zambrano, 1993).

En este sentido, es de señalar que ha habido avances muy significativos, en tanto las exportaciones no petroleras se han incrementado como resultado de los esfuerzos del sector privado y se han diversicado en comparación con la estructura preexistente, particularmente si excluimos el sector aluminio que ha decrecido como puede apreciarse en el Cuadro $\mathrm{N}^{\circ} 1 .^{5}$

Sin embargo, las exportaciones no tradicionales no han crecido de una manera sostenida durante los últimos cuatro años, abriéndose una brecha entre las mayoritarias importaciones (que han aumentado) y las escasas exportaciones (Promexport, 1992). ${ }^{6}$

Esta situación parece responder a dos factores significativos. Por un lado, a la poca capacidad de adaptación de un sector del

\footnotetext{
${ }^{5}$ Como señala Miguel Rodríguez Mendoza, el Presidente del Instituto de Comercio Exterior de Venezuela: " ...en 1991 el valor de las exportaciones no petroleras superó en un $40 \%$ el nivel alcanzado en 1988, el año anterior a las reformas. Las exportaciones del sector privado han siđo las más dinámicas, creciendo mucho más que las exportaciones de las empresas públicas no petroleras y representando cerca del $70 \%$ del total, mientras que su participación era de sólo el 35\% en 1988. Por otra parte, como resultado de las nuevas políticas, las exportaciones no petroleras constituyen ahora cerca del $20 \%$ de las exportaciones totales, mientras que hace algunos años este porcentaje apenas llegaba al 5\%" (Rodríguez, 1993a).

${ }^{6} \mathrm{De}$ acuerdo a las expectativas gubernamentales, un análisis de Economía Hoy señala que "1992 debería haber cerrado con 3.700 millones de dólares en ventas no tradicionales. Faltaron casi 1.000 millones para lograr esa meta. Los 2.609 millones de dólaxes alcanzados el año pasado y los 2.633 millones de 1991 se quedaron cortos respecto a las predicciones. Las cifras provisionales de la Oficina Central de Estadísticas e Información y del Banco Central de Venezuela demuestran un descenso a 1.900 millones de dólares de las exportaciones no tradicionales, si se excluye el aluminio, unos 900 millones de dólares menos que en 1991. Esta variación ha puesto al descubierto a un sector público disminuido en su capacidad exportadora de productos no tradicionales. Por el contrario, el sector privado ha ganado terreno en el ámbito exportador. Actualmente, $67 \%$ de las ventas externas no tradicionales corresponden al empresariađo venezolano; a diferencia de 1988 cuando sólo equivalían al $35 \%$. Sin lugar a dudas, este cambio ha servido para afirmar, en declaraciones oficiales, que las exportaciones no tradicionales aumentaron, si se exciuye el aluminio. Estudios preliminares del Instituto de Comercio Exterior señalan un incremento del $4 \%$, porcentaje que contradice a la disminución del $-0,9 \%$ y $-1 \%$ que calculan otros entes oficiales" (Acosta, EH, 2/2/93, p. 18-19). Estas cifras revelarían que se confirmó parcialmente el logro de uno de los objetivos del programa económico: la prómoción y la extensión de las cxportaciones no tradicionales efectuadas por el sector privado. Sin embargo, como lo señala el mismo informe, "un análisis compara tivo revela que del total de 2.663 millones de dólares de ventas externas no petroleras en 1991, 1.585 millones correspondicron a la exportación de manufacturas (59\%), tasa inferior a los resultados de 1989 y 1990 , cuando la participación de productos manufacturados alcanzó casi el $64 \%$. De mantenerse una tendencia elevada en las exportaciones no tradicionales de manufacturas, podría llegar a pensarse que en estos últimos cuatro años la industria venezolana ha construido la capácidad para competir en los mercados internacionales. Afirmación refutada por los mismos exportadores nacionales, quienes reiteradamente denuncian la inexistencia de una política industrial que pueda hacer frente a la competencia internacional" (ibid).
} 
empresariado nacional a las nuevas condiciones de competitividad internacional, tradicionalmente acostumbrado a la dependencia de los subsidios y del apoyo estatal y vinculado fundamentalmente al capital comercial importador (Ortiz, 1992b, p. 139; Silva Michelena, 1992).

Por otro, a la falta de avances por parte del Gobierno de las reformas internas necesarias para el desarrollo de una industria competitiva orientada a la exportación. En este marco es necesario ubicar no sólo las quejas del empresariado sobre una inflación superior al 30\%, el desmantelamiento arancelario abrupto, la competencia con productos importados, la falta de materialización de incentivos como el draw-back y la inexistencia de un Banco de Comercio Exterior (Acosta, 1993; Promexport, 1992), sino también una serie de razones estructurales de fondo, tales como la ausencia de una adecuada estructura para el comercio internacional que, no obstante todos los intentos de los últimos años y la existencia de una serie de ventajas comparativas, no ha podido superar situaciones como la de la configuración y funcionamiento de las aduanas, los puertos y el transporte marítimo, que "fueron diseñados bajo el enfoque importador, creando un alto sesgo antiexportador" (Chávez, $1992, \mathrm{D}-2)^{7}$

Por otra parte, no se ha producido una reestructuración de la economía en términos de incrementar la competitividad de los productos venezolanos, de diversificar más ampliamente la economía y de promover una inversión más sustancial en investigación, desarrollo y tecnología (Ortiz, 1992b). Asimismo, los objetivos iniciales de articular esta estrategia con una reconversión industrial que posibilite mejorar la competitividad del país a nivel regional a internacional se han ido desvaneciendo progresivamente (Páez, 1993).

No obstante estos señalamientos, es evidente que el repunte de las exportaciones no tradicionales se ha dirigido básicamente a aprovechar los espacios ofrecidos por los acuerdos de libre comercio y de integración en el ámbito subregional. En este sentido, baste observar el crecimiento del intercambio comercial con América Latina y el Caribe del Cuadro $\mathrm{N}^{2} 2$.

\footnotetext{
7 "Las exportaciones más competitivas del petróleo, aluminio, acero y petroquímicos se realizan por puertos privados, las aduanas presentan todo tipo de trabas para lograr la salida eficiente de mercancías y en el transporte marítimo la reserva de carga, la discrecionalidad y el monopolio estaial han sido las reglas tradicionales" (Chávez, 1992, D-2).
} 
Si sólo tomamos en cuenta el intercambio comercial más activo en el marco de la zona de libre comercio establecida en el Pacto, Andino en enero de 1992, vemos quẹ en ese año, más del $45 \%$ de las exportaciones no tradicionales están dirigidas hacia América Latina, a diferencia de 1989 cuando constituían el 35\% (Acosta, 1993, p. 19). En este proceso, pese a las dificultades y obstáculos señalados, es evidente que el sector privado se ha convertido en un puntal importante de la política de aceleración de los mecanismos de integración y de libre comercio existentes y de una más agresiva política comercial hacia el exterior del país (Rodríguez, 1993a).

Por otra parte, en el plano político y diplomático se ha buscado reforzar esta estrategia y su proyección regional a través de un arco de alianzas subregionales, regionales y hemisféricas utilizando el capital acumulado de experiencia y de vinculaciones políticas establecidas en las etapas precedentes. En este sentido, en función de reforzar la capacidad negociadora del país y de cubrir un creciente vacío geopolítico en èlárea de la Cuenca del Caribe, se intensifican tanto las vinculaciones con los países del área como con los países latinoamericanos en general, a través de vínculos previamente desarrollados en etapas anteriores, tales como las relaciones con la CARICOM y Centroamérica o la participación en el Pacto Andino y en ALADI, o de mecanismos emergentes como, en el plano político, el Grupo de Río, y en el plano de la concertación política y económica a nivel subregional, el Grupo de los Tres (Cobo, 1992; Serbin, 1992c y 1993a).

En suma, en este marco, el "gran viraje" plantea, en principio y no obstante las limitaciones señaladas, una estrategia de desarrollo articulada a una activa política de inserción en el sistema económico internacional, a partir de potenciar, a mediano y a largo plazo, tanto las ventajas competitivas de la industria petrolera (no obstante las dificultades y obstáculos que ésta pueda atravesar internacionalmente), como el fomento del crecimiento de las exportaciones de productos no tradicionales particularmente en el marco de una activa política subregional.

Consecuentemente, los tradicionales temas geopolíticos y de seguridad presentes en la agenda de la política exterior de Venezuela y asociados previamente con algunas de sus identidades descollantes (IEP, 1993; Josko, 1992) fueron crecientemente desplazados por las prioridades ećnónimicas vinculadas a la apertura comercial, la integración subregionaly la: diversificación de exportaciones y de merca- 
dos, junto con la búsqueda de alianzas que incrementen el poder de negociación internacional del país en función de estos objetivos económicos sobre la base del capital de relaciones y de vínculos acumulados en una etapa de mayor protagonismo internacional (Rojas, 1992; Guerón, 1991).

En este marco, el impulso al establecimiento de acuerdos de libre comercio y a la profundización de los esquemas de integración ya existentes se convirtió en una de las opciones fundamentales de la nueva política exterior de Venezuela. Esta opción de regionalización se basó, asimismo, en el capital de relaciones acumuladas a nivel de la región y de su desarrollo y potenciación.

\section{5.- Alcances y limitaciones de la política de regionalización.}

Estos objetivos de la política exterior de Venezuela en la etapa del "gran viraje" se encuentran condicionados, sin embargo, tanto por una serie de legados negativos de las etapas anteriores de Ta política exterior del régimen democrático, como por un conjunto de condiciones externas adversas que abren significativos interrogantes sobre su evolución futura (Serbin, 1993b).

A raíz de la implementación del "gran viraje", en una primera etapa se intentó mantener una política exterior sobredimensionada que se caracterizó tanto por la persistencia de la participación de Venezuela en escenarios y foros tan distantes de los objetivos inmediatos de Venezuela como la Comisión del Sur, como por el protagonismo presidencial en diversos ámbitos de la política hemisférica e internacional. Sin embargo, los acontecimientos políticos del 4 de febrero y del 27 de noviembre de 1992, impusieron un repliegue a la política exterior venezolana y una creciente limitación a este sobredimensionamiento (por demás severamente cuestionado por diversos sectores de la sociedad venezolana, y en particular, por la prensa escrita) (Romero, A., 1987).

Como consecuencia, gradualmente se ha producido una creciente concentración de la política exterior venezolana en el ámbito subregional de la Cuenca del Caribe.

En este sentido, tanto la ubicación geográfica del país en relación con los mercados más accesibles y fluidos para sus productos, como el bagaje acumulado de experiencias de vinculación, convergencia o alianza a nivel de la Cuenca del Caribe, condujeron a que la 
política exterior se concentrara progresivamente en aquellos países vecinos que por su proximidad o por su relevancia estratégica y económica tradicionalmente constituyeron las relaciones prioritarias del país.

De tal manera que, una de las secuelas de la combinación de la presión de los factores externos y la dinámica de la situación política doméstica, fue la tendencia a priorizar los temas subregionales en la política exterior del país. En este sentido, al margen del activismo inicial de Venezuela en la Comisión del Sur y el Grupo de los Quince, las excepciones más destacadas a esta concentración subregional están representadas, por un lado, por la continuidad del compromiso y de la participación en la OPEP, y, por otro, la persistente búsqueda de inversiones en los ámbitos europeos y asiático para desarrollar nuevos sectores de explotación minera y energética, más allá del flujo de inversiones procedente de América del Norte.

La participación en la OPEP desde su creación, ha implicado, independientemente de los altibajos del mercado petrolero y de los avatares políticos y económicos de sus países miembros, la posibilidad de incidir, aunque sea en forma parcial y limitada dadas las divergencias e incumplimientos de algunos de los miembros, en los precios internacionales de los hidrocarburos y en las presiones que sobre su baja pueden ejercer los países industrializados. La reciente gira del Ministro de Energía y Minas de Venezuela, actualmente a cargo de la presidencia de la OPEP, a los países productores de petróleo para lograr una reducción en la producción y una consecuente subida de los precios internacionales es una clara ilustración de esta situación.

Por otra parte, la búsqueda de capitales extranjeros ha estado ligada, por un lado, a las necesidades de inversión y de tecnología para el desarrollo de megaproyectos para la industria petroquímica, del aluminio, y la explotación de gas, bauxita y carbón, y por otro, a las crecientes necesidades de inversión para la expansión e internacionalización de la industria petrolera. En este último aspecto, $\mathrm{Pe}$ tróleos de Venezuela Sociedad Anónima (PDVSA), ha promovido una activa campaña de internacionalización para penetrar y asegurar la distribución de los hidrocarburos venezolanos en los mercados de los países industrializados, para lo cual se ha asociado con corporaciones transnacionales tanto en Estados Unidos como en Europa. Sin embargo, todavía la inversión y la asociación de capitales extranjeros en la explotación petrolera a nivel nacional está severamente restringida por la legislación aprobada al nacionalizar la industria petrolera en 1975. Finalmente, es de señalar que la expansión internacional de 
A. Serbin / La política exterior de Venezuela y sus ...

PDVSA ha sido coartada a principios de 1992 por disposición presidencial, en función de las necesidades presupuestarias del Estado (WR-92-35, p. 1).

Pero al margen de estas orientaciones en el plano internacional, frecuentemente condicionadas por agencias gubernamentales no vinculadas formalmente a la formulación e implementación de la política exterior como PDVSA y el MEM, el foco de las prioridades ha estado centrado, en los últimos años, definidamente a nivel subregional.

En este sentido, las prioridades han girado en torno a: a) las relaciones con Estados Unidos, en especial en relación con las vitales exportaciones petroleras y el desarrollo del ALCAN y de la Iniciativa de las Américas; b) el proceso de integración con Colombia; c) la reactivación y las dificultades por las que ha atravesado el Pacto Andino, con un enfoque diferente al promovido en la década del sesenta; d) la creación del Grupo de los Tres y las dificultades de un Acuerdo de Libre Comercio con México, y e) las relaciones con 'Centroamérica y el Caribe, en el marco de la política de cooperación que tradicionalmente ha llevado Venezuela en la subregión.

Esta concentración subregional ha dado pie para maximizar los beneficios de un proceso de creciente concertación e integración en torno a la Cuenca del Caribe, entendida ésta en su acepción más amplia con la inclusión tanto de los Estados Unidos como de los países andinos vinculados a ella (Serbin, 1990 y 1991c).

En líneas generales, este proceso ba seguido la tendencia a reaccionar, a corto plazo, por un lado a las transformaciones del sistema internacional y a las nuevas presiones y demandas generadas por un nuevo orden internacional, $y$ por otro, a la crisis interna del país. En este sentido, es difícil establecer si existe una estrategia explícita de regionalización a más largo plazo, pero sí es dable observar que este proceso de repliegue internacional y de concentrado activismo regional no se basa exclusivamente en consideraciones económicas y comerciales, no obstante la implementación de la Nueva Política Comercial y el "gran viraje", sino que combina elementos económicos con consideraciones geoestratégicas, políticas y, circunstancialmente, de coincidencias históricas y culturales.

\section{Las relaciones con Estados Unidos.}

La relación con Estados Unidos, principal mercado para los productos petroleros del país y fuente principal de sus importaciones, a su vez percibido como aliado tradicional de Venezuela en el marco de 
la Guerra Fría, se convirtió en una de las prioridades de esta política, particularmente en función del apoyo político externo que este país podría prestar para evitar la imposición de un Gobierno de facto en Venezuela a raíz de los acontecimientos de 1992, en el marco de la tendencia hemisférica propicia a impulsar y apuntalar los , procesos de redemocratización y de consolidación democrática en el continente.

Por otra parte, Estados Unidos representó para Venezuela en 1991 , el mercado de más de la mitad de las exportaciones y de cerca del $60 \%$ de las exportaciones directas de petróleo y sus derivados; el mercado de procedencia de más del $40 \%$ de las importaciones; el país donde se originaba aproximadamente la mitad de las inversiones extranjeras, y cuya banca concentra casi la totalidad de la deuda externa venezolana. A su vez, la relación política con Estados Unidos ha tenido históricamente ( $y$ continúa teniendo en la actualidad) una especial importancia en relación con la jerarquía de los intereses de Venezuela afectados por problemas que requieren de una atención conjunta, particularmente a nivel subregional: estabilidad política democrática, narcotráfico, ambiente, conflictos regionales y derechos humanos.

Por su parte, Venezuela ha mantenido una importancia relativa y estable, aunque limitada, en la jerarquía de intereses de Estados Unidos. En términos comerciales, para 1991; era el segundo socio comercial latinoamericano de Estados Unidos, después de México; las inversiones de Venezuela a través de PDVSA en las compañías norteamericanas Citgo, Champlin y Unoven, revisten cierta significación,y, desde el punto de vista de abastecedor petrolero, Venezuela ha constituido, no obstante sus devaneos con la OPEP, una fuente confiable ubicada, luego de la Guerra del Golfo Pérsico, en un segundo lugar (Cardozo, 1992a). ${ }^{8}$

En este marco, sin embargo, la aspiración venezolana de convertirse, a través de un acuerdo preferencial, en un aliado estratégico de Estados Unidos por su condición de proveedor petrolero seguro (que históricamente nunca dejó de cumplir con sus compromisos pese a su activa participación en la OPEP), no se ha visto materializa-

\footnotetext{
${ }^{8}$ Como señala la misma Cardozo, "en estas condiciones la Iniciativa para las Américas reviste especial importancia para un país estrechamente vinculado a Estados Unidos, en medio de la ejecución de un proyecto de apertura y desregulación que ha definido una más agresiva política exterior comercial que permita una más eficiente inserción internacional" (Carđozo, 1992a, p. 2).
} 


\section{A. Serbin / La política exterior de Venezuela y sus ...}

đa. Venezuela no sólo no ha podido establecer un marco seguro para sus exportaciones petroleras al mercado estadounidense, sino que también se ha visto amenazada recientemente por la nueva administración del Presidente Clinton de que se establezca un impuesto sobre el petróleo importado (Tarre, 1993). Situación que ha provocado un debate en el país, a la vez de un renovado llamado a promover los intereses venezolanos en el Congreso de Estados Unidos a través de un lobbying efectivo (Toro Hardy, 1993). A esta situación cabe agregar la preocupación de que de imponerse este impuesto, México y Canadá se verían favorecidos en sus exportaciones petroleras a Estados Unidos en el marco del AlCAN (Rodríguez, 1993b).

Por otra parte, las expectativas de que el acuerdo marco sobre comercio e inversiones firmado con Estados Unidos en abril de 1991 pueda derivar al establecimiento de un acuerdo de libre comercio similar al del ALCAN, se han visto asimismo frustradas, en tanto representantes de Estados Unidos han declarado reiteradamente que, luego de México, el país que eventualmente podía seguir en la lista era Chile, hasta tanto Venezuela no avance en el proceso de reestructuración y estabilización económica y no afirme su estabilidad política (Skol, 1992).

Finalmente, la expectativa de ampliar la exportación de productos no tradicionales hacia el mercado estadounidense de manera de equilibrar más equitativamente la balanza comercial, ha chocado con el incremento de medidas proteccionistas no arancelarias en sectores como el acero, el cemento y el aluminio. Por otra parte, pese a que la pertenencia de Venezuela al Sistema Generalizado de Preferencias favorece la exportación de productos no tradicionales al mercado norteamericano, el peso determinante lo siguen teniendo las exportaciones petroleras, que constituyen en los años recientes, un $90 \%$ de las exportaciones hacia Estados Unidos (Cardozo, 1992a, p. 10) (Ver Cuadros $\mathrm{N}^{\circ} 3$ y No4). ${ }^{9}$

\footnotetext{
${ }^{9}$ Como acota Cardozo, "en las relaciones comerciales se evidencia la asimetría anotada como rasgo global, pues si bien Venezuela es, desde el punto de vista comercial, un socio latinoamericano importante para Estados Unidos, en el comercio estadounidense global ocupa apenas el lugar diecinueve. En materia petrolera, Venezuela es el segundo principal abastecedor, y está integrada al mercado petrolero norteamericano a través de inversiones directas, sin embargo, la capacidad para explotar las ventajas políticas de esas circunstancias se encuentra cađa vez más limitada por la consolidación đe un nuevo orden energético mundial. El control del mercado por los grandes consumidores, la necesidad de cuantiosas inversiones para lograr competitividad, la desnacionalización de las industrias petroleras y la expansión de las actividades de las transnacionales petroleras, las normas ambientales propuestas y las inversiones para el desarrollo de fuentes alternativas, son las características más notables de ese nuevo orden" (Cardozo, 1992a, p. 11).
} 
En este contexto, la atención de la política exterior venezolana se ha focalizado asimismo en priorizar crecientemente las relaciones con los países de la Cuenca del Caribe, como ámbito favorable tanto para la consolidación de las exportaciones no tadicionales como para la afirmación de alianzas geopolíticas que permitan una negociación más ventajosa con Estados Unidos.

\section{Las relaciones con Colombia.}

Este proceso se ha visto fortalecido, por un lado, por la profundización de los avances de la integración con Colombia, basado en la complementariedad de ambas economías, la similitud de los programas de ajuste y la proximidad geográfica reflejada en el intenso intercambio comercial entre ambos. Sin embargo, la acelerada integración entre los dos países se ha visto amenazada tanto por las dificultades políticas internas por las que atraviesa cada uno de ellos, como por las tensiones limítrofes que han excerbado eventualmente los ánimos de los sectores nacionalistas de ambos lados de la frontera.

Por otra parte, este proceso ha contribuido a la profundización de los avances de la integración entre los países del Pacto Andino sobre la base del éxito alcanzado por el eje Venezuela-Colombia en un contexto sustancialmente distinto de la paralización a la que había llegado la Junta del Acuerdo de Cartagena (JUNAC) en años anteriores (CEPAL, 1991a).

En el marco de la aceleración de los procesos de integración subregional, probablemente el esquema preexistente que más rápidamente ha avanzado en este proceso tendiente al establecimiento de un mercado común y de una unión aduanera ha sido el Pacto Andino, en cuyo marco Venezuela y Colombia ya han impulsado una zona de libre comercio y una política de cielos abiertos a partir de enero de 1992 . $^{10}$

A un año de esta iniciativa, el comercio entre ambos países ha superado en 1992 los 965 millones de dólares, con un incremento del

\footnotetext{
${ }^{10}$ Tomando solamente en consideración los aspectos económicos, Rojas señala que "la dinámica real del Pacto Andino se concentra en las relaciones comerciales crecientes entre Colombia y Venezuela, y en los efectos dinamizadores de las mismas sobre el resto de la subregión. Para Venezuela es sin dưa la primera opción en materia de integración: Colombia es nuestro segundo mercado en importancia para las exportaciones no petroleras" (Rojas, 1992, p. 167).
} 
$53 \%$ con respecto al año anterior (EDC, 21-12-92).${ }^{11}$ De hecho, a la vez que la exportaciones de Colombia a Venezuela se han duplicado, Venezuela se ha convertido en el segundo proveedor de Colombia luego de Estados Unidos, de manera que el comercio entre los dos países se ha convertido en el más alto de la región (EH, 28-1-93, p. 9).

\section{El Pacto Andino.}

Sin embargo, los avances en la integración colombo-venezolana, signados aún por las tensiones limítrofes existentes entre ambos países (con frecuencia utilizados por algunos sectores nacionalistas de ambas sociedades para cuestionar el proceso de integración) y por la inestabilidad política doméstica, no han sido equiparados, en 1992, por avances similares con los restantes países miembros de la JUNAC, básicamente dificultados por el establecimiento de un arancel externo común y de una zona de libre comercio que debería entrar en vigencia en 1993 . $^{12}$

No obstante la autoexclusión temporal de Perú del esquema (que ha preferido continuar por la vía de los acuerdos bilaterales luego del impasse político surgido con Venezuela a raíz del autogolpe de Fujimori en 1992) y el acercamiento de Bolivia al MERCOSUR (cuyo ingreso a este esquema puede demorarse 2 años debido a regulaciones internas pero cuya incorporación, de acuerdo a las mismas regulaciones, excluiria la participación en otros esquemas de integración subregional), el intercambio comercial en el Pacto Andino se ha incrementado significativamente en el año 1992 y Ecuador ha avanzado en sus acuerdos de libre comercio con Colombia y Venezuela, planteándose su eventual incorporación al Grupo de los Tres (Ochoa Antich, 1993).

De hecho, en 1992 el intercambio comercial entre los países miembros del Pacto Andino alcanzó el récord histórico de 2.120 millones de dólares, incrementándose en un $17,9 \%$ con respecto al año anterior en una escala de 320 millones más que en 1991 (EH,

\footnotetext{
${ }^{11}$ Según Laura Rojas, Vice-Ministra de Fomento de Venezuela, las exportaciones no tradicionales destinadas a Colombia "aumentaron $292 \%$ en 1992 con relación a 1991" (a Eciuador en un 59\%), posibilitando la diversificación đe exportaciones y la açtiva participación del sector privado como principal exportador (68\% de las exportaciones no tradicionales) (EHm 22-1-93, p. 15).

${ }^{12}$ La reunión de la Comisión del Acuerdo de Cartagena estaba prevista para el 15 y 16 de febrero en Caracas, pero fue pospuesta para marzo. Esta reunión puede cambiar esta situación con la eventual aprobación del Arancel Externo Común.
} 
29-1-93, p. 18). En este marco, es de señalar que Venezuela se constituye en el segundo país del Pacto Andino por el volumen de su comercio subregional con una tasa de crecimiento de exportaciones más alta de la región (Rodríguez, 1993b). Sin embargo, pese a que, de acuerdo a la JUNAC, el $83 \%$ de las ventas intraandinas está constituido por manufacturas, Venezuela sigue siendo predominantemente un país monoexportador cuyo eje sigue basado, en el Pacto Andino, en el petróleo y sus derivados (ibid.; Carmona, 1993, 2-2).

Finalmente es de señalar que la constitución de una zona de libre comercio en el marco andino, así sea sin incluir a Perú, plantea "un modelo de integración abierto" que, en principio, no debe ser restringido por el establecimiento de un arancel externo común, al punto que el Presidente del Instituto de Comercio Exterior considera que el Pacto Andino debe comenzar negociaciones para una relación comercial más estrecha con MERCOSUR (Rodríguez, 1993b).

\section{El Grupo de los Tres y la relación con México.}

Otro de los ámbitos subregionales donde Venezuela ha desarrollado una activa política es el G-3, conformado inicialmente en 1989 por México, Colombia y Venezuela como un grupo de consulta y de evaluación regional a partir de una disposición común de avanzar en la creación de una zona de libre comercio, básicamente en torno a los temas comerciales y energéticos, y de promover la cooperación con los países de Centroamérica y del Caribe (Grupo de los Tres, 1991).

La experiencia de coordinación política previa de estos tres países en la Cuenca del Caribe, a través del Grupo Contadora, el Acuerdo de San José de asistencia petrolera entre México y Venezuela y los avances del proceso de integración económica entre Venezuela y Colombia, han servido de base para profundizar progresivamente este esquema a través de sucesivas reuniones de cancilleres y presidentes a lo largo de los años 1990, 1991 y 1992, con la conformación de 11 Comisiones Técnicas de Alto Nivel en torno a temas como comercio, energía, cooperación con Centroamérica y el Caribe, transporte aéreo y marítimo, medio ambiente, telecomunicaciones, ciencia y tecnología, finanzas, turismo y cultura (Durán, 1992). 
Por otra parte, los avances que desde 1989 se han desarrollado en el establecimiento de un Acuerdo de Libre Comercio entre México, Colombia y Venezuela en el Grupo de los Tres, responden, pese a las asimetrías en la dimensión y potencialidad económica de los dos países andinos con su socio de América del Norte, a un conjunto de razones.

En primer lugar, el G-3 se basa en la expectativa de Venezuela y de Colombia de aprovechar este esquema de vinculación con México para poder posesionarse más ventajosamente en una eventual incorporación al ALCAN; mientras que para México, el G-3 ofrece una posibilidad de contrabalancear políticamente su creciente vinculación económica con América del Norte a un bajo costo. Pese a que el primero de los argumentos pueda ponerse en duda, inicialmente la iniciativa de Venezuela y Colombia para promover el G-3 respondió a esta expectativa. De hecho, Venezuela y Colombia tienen como meta primordial a largo plazo una ampliación del mercado regional y una relación eventualmente más ventajosa con Estados Unidos vía México, mientras que el Gobierno mexicano posiblemente busque en el G-3 un apoyo a su política subregional en Centroamérica y su intención, a largo plazo, "se centre más en abrir el tapón de Darién que romper en dos a Latinoamérica" (Zapata, 1992).

No obstante estos propósitos tácitos, un reciente documento del SELA evalúa que "una de las líneas de desarrollo posible es la progresiva consolidación del G-3 y la constitución de un área de libre comercio a mediano plazo entre México, Colombia y Venezuela. En este caso, si bien la posibilidad de una convergencia cambiaria es alta, la diferencia de metas nacionales en cuanto a la estructura de protección frente a terceros y la progresiva integración de la economía mexicana a los Estados Unidos a través del acuerdo de libre comercio norteamericano hace muy poco probable que el G-3 derive a una unión aduanera" (SELA, 1991b). En este sentido, las negociaciones recientes entre México, Venezuela y Colombia en la reunión del 11 y 12 de febrero de 1993 en Caracas, han evidenciado crecientes dificultades tanto en términos del reconocimiento de las asimetrías existentes como de la eventual armonización de los elementos de este acuerdo con la participación de México en el ALCAN. Este último aspecto, de hecho, implicó sucesivas postergaciones por parte de México de la reunión prevista para Caracas, en función de las demo- 
ras en la firma del acuerdo a raíz de la transición de la administración Bush a la Clinton (EH, 2-12-92). ${ }^{13}$

\section{El Caribe y Centroamérica: Las preocupaciones del Grupo de. los Tres y el papel de Venezuela.}

Por otra parte, existe, más allá de las intencionalidades eminentemente económicas, una extensa experiencia de convergencias políticas en la región entre los tres países, ilustradas no sólo por el Grupo Contadora y el Acuerdo de asistencia petrolera de San José promovidos por Venezuela y México, sino también por la creciente preocupación de los tres países por la situación subregional en el marco del vacío geopolítico generado por el fin de la Guerra Fría en la Cuenca del Caribe. En este sentido, la preocupación por la estabilidad de los pequeños Estados del Caribe insular y de Centroamérica (con énfasis distintos en cada caso) se asocia con una serie de convergencias que, aunque parciales, ilustran la preocupación asimismo por el proceso de transición en Cuba y su impacto regional (Serbin, 1992c y 1993a).

Es en este contexto donde hay que ubicar el hecho de que el G-3 evidencie una especial preocupación por la cooperación con los países centroamericanos y del Caribe, ilustrada asimismo por la firma de acuerdos de comercio no recíprocos con los países centroamericanos y con la CARICOM, y la incorporación tanto de Méxxico como de Colombia y Venezuela, como observadores de este último organismo en 1991.

\footnotetext{
${ }^{13}$ Como señala un analista venezolano en relación con la posición del país frente al G-3 en la reunión de febrero: "a) interesa garantizar la caliđad de la negociación, vale decir una apreciación global, claramente positiva, por encima de la celeridad de la misma; b) el interés económico de Venezuela en el libre comercio con México no ha sido demostrado. Es clara la tremenđa asimetria existente en la dimensión de mercados y el nivel de desarrollo industrial de ese país y consecuentemente en la desigualdad de oportunidades; ello obliga a asegurar que México acepte eliminar los aranceles más aceleradamente en favor de Venezuela y Colombia, que lo que estos países hagan con respecto a México; c) si es necesario, debe preveerse una cuarta categoría de productos sensibles con desgravación a 10 o 15 años. Recuérdese que México así lo recogió en sus negociaciones con Estados Unidos y Canadá, al igual que la desgravación con asimetría; d) deben evaluarse las implicaciones del NAFTA sobre el G-3 antes de contraer obligaciones definitivas. Especial relevancia tiene el capifulo de norma de origen de las mercaderías; e) la equidad es el único elemento capaz de garantizar la perdurabilidad del esquema que se negocie. La concertación estrecha y oportuna con el sector privado es imprescindible; f) el planteamiento de que eí G-3 es el camino hacia la eventual adhesión de Venezuela al NAFTA está también por demostrarse, producto de un debate estratégico interno, aún pendiente, sobre las opciones en las relaciones con Estados Unidos" (Carmona, 1993, p. 2-2).
} 
El proceso iniciado con la firma del acuerdo marco de Tuxla Gutiérrez entre México y los países centroamericanos en 1991, se complementa con el acuerdo de libre comercio en vigencia desde enero de 1993 entre Venezuela y la CARICOM, (surgido de la propuesta hecha por el Presidente Carlos Andrés Pérez a la cumbre de St. Kitts en junio de 1991 y firmado en Caracas el 14 de octubre de 1992). Estas iniciativas deberán ser refrendadas por la firma de un acuerdo no recíproco de características similares entre Venezuela y Colombia y los países centroamericanos en la reunión de febrero del G-3 en Caracas, que permitirá el acceso de 360 productos centroamericanos al mercado colombo-venezolano sin pago de aranceles, en una progresiva ampliación a lo largo de cinco años y que culminará con el establecimiento de una zona de libre comercio entre ambos grupos de países.

Es de resaltar en este proceso, que Venezuela y Colombia actuarán conjuntamente y que este último país se adherirá a la iniciativa venezolana con la CARICOM. En este sentido, es de señalar que el Caribe absorbió en 1991, el 14,62\% de las exportaciones de Venezuela (Ver Cuadro No8). ${ }^{14}$ Sin embargo, el comercio de exportación de Venezuela a CARICOM representa escasamente un $2,3 \%$ de las exportaciones totales. ${ }^{15}$

Pero el interés venezolano en el Caribe no hispánico se vincula con una percepción más amplia de sus intereses estratégicos en la región, en tanto el área insular constituye el paso obligado para la mayoría de sus importaciones y para las vitales exportaciones petroleras, y cualquier atisbo de inestabilidad regional, más allá de la Guerra Fría, constituye una amenaza tanto para sus intereses econó-

\footnotetext{
${ }^{14}$ Según datos del Instituto de Comercio Exterior, las exportaciones de Venezuela a los 13 paises de la CARICOM obtuvieron un saldo positivo en la balanza comercial, llegando casi al millon đe đólares. La tendencia registrada fue al alza, con un crecimiento acumulado de $53,4 \%$ $y$ un comercio global de 1,4 millones de dólares. En cuanto al volumen comercial, las exportaciones de Venezuela han aumentado, en el período 1987-1991, en un 48, 3\% y un valor acumulado de 1,2 millones de dólares. Sin embargo, la distribución de los rubros exportadores es bien poco alentadora para las exportaciones no tradicionales. Así tenemos que el 78,4\% de las ventas venezolanas en el Caribe lo constituyen el petróleo y sus derivados, mientras que las exportaciones no tradicionales apenas llegaron al $21,6 \%$ las exportaciones petroleras fueron las que más crecieron en este período $(53,1 \%)$, mientras que las exportaciones no tradicionales lo hicieron en un $25 \%$ " (EH 11-11-92).

${ }^{15}$ No obstante, el incremento del intercambio comercial con la región ha sido del $88 \%$ en 1991 en relación con 1990, dando un superávit de 648,5 millones de dólares. Las importaciones desde CARICOM, por otra parte, apenas si llegaron a un 1,17\% de las importaciones totales de Venezuela (Molina, 1992).
} 
micos como para la propia estabilidad política del país (Serbin, 1993d).

Una situación similar, aunque a una escala menor, está representada por Centroamérica, donde Venezuela se ha ido involucrando crecientemente a partir de la crisis regional de la década dẹl setenta (ibid.).

Por otra parte, es de señalar que pese a lo restringido del mercado centroamericano, Venezuela ha venido presentando un saldo claramente superavitario en sus relaciones comerciales con la subregión con un significativo crecimiento de las exportaciones no tradicionales. ${ }^{16}$

En este proceso se enmarca, la firma, en julio de 1991, de las "Bases para un acuerdo marco sobre comercio e inversión" con Costa Rica, El Salvador, Honduras, Guatemala y Nicaragua, que fue refrendado, en condiciones no recíprocas en la reunión del G-3 en Caracas en febrero de 1993.

Sin embargo, es de señalar que este acuerdo ha suscitado reacciones negativas por parte del sector privado venezolano (similares a las esgrimidas en el establecimiento del acuerdo con la CARICOM) y, en especial, por parte de la Asociación Venezolana de Exportadores.

En el marco de este cuadro subregional, Venezuela y Colombia no sólo han comenzado a desarrollar posiciones conjuntas en la negociación con México en el G-3, sino que también han avanzado en las negociaciones con Centroamérica y el Caribe anglófono. Esta experiencia conjunta ha abierto, asimismo, la posibilidad de iniciar una negociación de los dos países con Estados Unidos, con miras a su incorporación a ALCAN (Rodríguez, 1993b).

\footnotetext{
${ }^{16}$ De 1984 a 1990 , las importaciones que Venezuela ha realizado desde estos paises superaron, tan sólo en el año 1988, los 10 millones de dólares, mientras que las exportaciones sobrepasaron, para el mismo año, los 250 millones de đólares. Eń el períođo 1984-1990, estas exportaciones presentan una tendencia al crecimiento, al punto que de 362.275 miles de dólares en 1984 pasaron a 390.038 miles en 1990 , con una clara predominancia del petróleo y sus derivados. Esta predominancia tendió a decrecer, pasando de representar un $88,8 \%$ de las mismas en 1984, a un $74 \%$ en 1990 , de manera que se ha evidenciado un crecimiento progresivo de las exportaciones no tradicionales (Ortiz, 1992a, p. 188).
} 


\section{Conclusiones.}

En función del cuadro anterior, la experiencia venezolana de la política exterior iniciada con el "gran viraje" se ha articulado con el establecimiento de las bases de un acelerado proceso de regionalización en la Cuenca del Caribe.

En el marco de este proceso, por un lado, se ha ido producierdo una creciente diferenciación entre la subregión de la Cuenca del Caribe y el Cono Sur, en el ámbito hemisférico. En esta situación, y no obstante las sugerencias recientes de una aproximación entre ambas subregiones, ha incidido tanto la estrecha vinculación económica y geopolítica de la Cuenca con América del Norte y, en especial con Estados. Unidos, como la mayor diversidad de vínculos externos en el Cono Sur, con una fuerte prevalencia de las relaciones comerciales y de las identificaciones ideológico-culturales con Europa Occidental. Por otra parte, la fragmentación creciente entre los países andinos ha dado pie para un proceso de mayor atracción centrípeta de ambas subregiones sobre el eje andino.

En la Cuenca del Caribe, la referenciación externa más importante sigue siendo los Estados Unidos, tanto en función de los efectos económicos y comerciales del ALCAN como en relación con el papel que desempeña esta nación en la seguridad subregional. Esta afirmación es válida tanto para los pequeños países del Caribe insular y de Centroamérica, como para las llamadas potencias regionales como México, Colombia, Venezuela y, eventualmente, Cuba.

Sin embargo, al margen de que el proceso de regionalización en la Cuenca del Caribe esté fuertemente signado por la presencia y las vinculaciones con Estados Unidos, el aceleramiento de la integración y la cooperación regional ha llevado a la revitalización de esquemas como el Mercado Común Centroamericano, la CARICOM y el Pacto Andino, y a la emergencia de un nuevo esquema -el Grupo de los Tres-que, pese a sus asimetrías internas, ha asumido progresivamente un rol protagónico a nivel regional, tanto en lo que se refiere a su dinámica geopolítica (si tenemos en cuenta su papel en el proceso de pacificación en Centroamérica y su actitud frente a la situación cubana), como en la promoción de acuerdos de libre comercio y de asistencia y cooperación económica a nivel subregional.

En este contexto, en razón de las presiones internas y externas, el "gran viraje" de la política exterior venezolana se ha concentrado básicamente en potenciar, en lo económico y lo político, su vincula- 
ción con la subregión y con estos procesos. Desde esta perspectiva, el saldo para Venezuela, tanto en términos de sus intereses comerciales como de sus objetivos políticos y diplomáticos es altamente positivo, no obstante las limitaciones que se puedan señalar con respecto a los efectos internos de esta política, a los verdaderos alcances de la diversificación y apertura comercial y al grado real de involucramiento del sector privado y de cambio del sector gubernamental.

Desde el punto de vista de los objetivos de la política exterior venezolana, tanto en función de las nuevas prioridades económicas relacionadas con el proceso de ajuste y reestructuración, como de los objetivos geopolíticos vinculados con promoción y consolidación de alianzas y concertaciones subregionales, el balance es positivo a pesar de la refocalización y rejerarquización de sus prioridades y objetivos en el marco del repliegue general del activismo internacional de Venezuela, si nos atenemos a los logros obtenidos en estos cuatro años a nivel subregional.

Por un lado, pese a las dificultades internas, se han incrementado el intercambio comercial con toda la subregión, y, en particular, las exportaciones no tradicionales del país, posibilitando una diversificación de la economía venezolana que contribuye a modificar, así sea en forma parcial y en lo inmediato, su identidad de país monoproductor.

Por otro, nuevamente pese a sus dificultades internas y la imagen proyectada por los dos intentos de golpe en un país asumido, desde 1958, en su carácter de democracia estable, Venezuela ha consolidado, sobre la base de una amplia experiencia previa de influencia y proyección subregional, su espectro de alianzas y nexos políticos.

En esta perspectiva, a corto y mediano plazo, este cuadro ha potenciado las posibilidades de Venezuela tanto en términos de la -expansión y diversificación económica, como de la concertación política necesaria inclusive para la negociación con actores extrarregionales.

Si tenemos en cuenta que estos logros se han dado en el contexto de una difícil situación económica y política interna, y de un entorno internacional que ha dificultado el flujo de capitales y tecnología hacia los países latinoamericanos, las conclusiones son positivas, más allá de las críticas que se esbocen en torno a la falta de continuidad de los objetivos de la política exterior venezolana; a la 
faîta de coherencia y de unà estrategia clara y consecuente en la relación con los países industrializados y, en especial, con Fstados Jnidờs, y a la dispersión eventual de las acciones e iniciativas de esta política exterior. En este marco, es necesario subrayar que, no obstante todas las dificuliades señaladas, los cuatro años de "gran viraje" han contribuido a perfilar una poítica exterior de rasgos regionales más enfáticos y de dimensiones más acotađas y realistas, más acordes a las realidades geopolíticas y económicas en las cuales se encuentra inserta Venezuela, en función de promover sus intereses y objetivos a través de un proceso de regionalización en la Cuenca del Caribe.

Sin embargo, el repliegue de la política exterior venezolana evidenciada en este período y la concentración regional, ha mostrado, más allá de la aceleración del proceso de regionalización, un descuido creciente en la diversificación de vínculos económicos y políticos en el ámbito global, tanto por efectos de la creciente fragmentación del sistema internacional en torno a tres bloques económicos como a consecuencia de la inestabilidad social y política interna. En este sentido, no es casual que el proceso de regionalización en el que se ha involucrado la política exterior venezolana comience a ser calificado por algunos sectores nacionales como "parroquial" (Weill, 1993), en el marco de severas críticas a los alcances reales de este proceso en términos de una inserción internacional más ventajosa del país.

\section{BIBLIOGRAFIA}

Acosta, Silvina, "Entre el boom de la apertura y las exportaciones que faltan", Economía Hoy, Caracas, 2 de febrero de 1993, pp. 18-19.

Barrera, Cristina; Oswaldo Dávila y Marc Mainardus (coord.), Integración y burocracia. Trabas no arancelarias. Caracas: Fundación Friedrich Ebert/Nueva Sociedad, 1991.

Bialey, Norman, "Venezuela and the United States. Putting Energy in the Enterprise", ponencia al seminario Lessons of the Venezuelan Experience, Washington, octubre, 1992.

Braveboy-Wagner, Jacqueline, "The United States, the New World Order, and Implications for Latin America and the Caribbean", trabajo presentado en XVI Annual Conference of the Caribbean Studies Association, La Habana, 21-24 de mayo, 1991. 


\section{ESTUDIOS INTERNACIONALES}

Buzan, Barry, "New Pătterns of Global Security in the Twenty First Century", International Affairs, London, vol. 67, №3, July, 1991.

Cardozo de Da Silva, Elsa, "Las relaciones Venezuela-USA y el comercio: evolucion reciente, estado actual y perspectivas", ponencia al 1er. Taller sobre Libre Comercio e Impacto Ambiental en Venezuela, Caracas, 8-10 de julio, 1992a.

Cardozo de Da Silva, Elsa, Continuidad y consistencia en quince años de política exterior venezolana 1969-1984. Caracas: UCV/CDCH;1992b.

Cardozo de Da Silva, Elsa, "Política exterior en tiempos de turbulencia: el desafío de responder al cambio", Polfitica Internacional, Caracas, No27, julio-septiembre, $1992 \mathrm{c}$.

Carmona Estanga, Pedro, "Carrousel de reflexiones", El Universal, Caracas, 6 de febrero, 1993, p. 2-2.

CEPAL, "La integración económica en los años 90: perspectivas y opciones", LC/R 1024, 24 de agosto, 1991a.

CEPAL, "Coordinación de políticas macroeconómicas en la integración latinoamericana: una necesidad o una utopía?", LC/R 1064, 23 de octubre, 1991b.

CEPAL, "Los nuevos proyectos de integración económica en América Latina y el Caribe y la dinámica de la inversión ${ }^{n}, \mathrm{LC} / \mathrm{R}$ 1145, 20 de mayo, $1992 \mathrm{a}$.

CEPAL, "Convergencias de los esquemas de integración", LC/R 1192, 2 de octubre, $1992 \mathrm{~b}$.

CEPAL, Ensayos sobre coordinación de politicas macroeconómicas. Santiago de Chile: CEPAL, 1992c, $250 \mathrm{pp}$.

Cobo, Lourdes, "Prioridades de la política exterior de Venezuela para el año 2000", en: Romero, Carlos (comp.), Reforma y política exterior en Venezuela. Caracas: COPRE/INVESP/Nueva Sociedad, 1992.

CordIPLAN, El Gran Viraje. Lineamientos Generales del VIII Plan de la Nación. Caracas: Cordiplán, 1990.

Colett, Raymond, "Nuexo auge del Pacto Andino", Economía Hoy, Caracas, 6 de febrero, 1993, p. 32.

Chávez, C: R., "La economía venezolana perdió terreno", El Universal, Caracas, 6 de noviembre, 1992, p. 2-4.

El Diario de Caracas, 21 de diciembre de 1992, p. 29.

Durán, Marianella, "El Grupo de los Tres ratificará necesidad de adelantar procesos de libre comercio", El Diario de Caracas, 11 de junio de 1992, p. 30-31.

Economía Hoy, Caracas, 11 de noviembre de 1992, p. 19.

Economía Hoÿ, 28 de enero de 1993a, p. 9.

Economía Hoy, 29 de enero de 1993b, p. 18.

Frances, Antonio, Venezuela posible, Caracas: Corimón / IESA, 1990. 
FundafuTuRō, Guando Venezuela perdió el numbo. Un análisis de lä economta venezolana entre 1945 y 199.1. Caracas: Ediciones Cavendes, 1992.

Griffith, Ivelaw (ed.), Strategy and Security in the Caribbean. New York: Praeger, 1991, 202 pp.

Grupo de los Tres, "Coordinar las acciones de cooperación e integración", Comercio Exterior, México, vol. 41, Ne1, enero, 1991, pp. 30-31.

Guerón, Carlos, "La política de Estado y el estado de la política", Política Intemacional, Caracas, №3, julio-septiembre, 1991.

Hurrell, Andrew, "Latin America in the New World Order: a regional bloc of the Americas?", International Affairs, vol. 68, Nی1, January, 1992.

(IEP) Instituto de Estudios Políticos, La agenda de la política exterior de Venezuela. Caracas: EBUC, 1983.

IRELA, "Venezuela en crisis: raíces y consecuencias", Dossier No39, Madrid, junio, 1992.

International Economic Review, "Chartbook. Composition of U.S. Merchandise Trade 1987-1991", United States International Trade Commission, Washington, March, 1992.

Josko de Guerón, Eva, "Cambio y continuidad en la política exterior de Venezuela: una revisión", en: Romero, Carlos (coord.), Reforma y política exterior en Venezuela. Caracas: COPRE/INVESP/ Nueva Sociedad, 1992.

Martner, Gonzalo, América Latina: el precio de vivir de las materias primas. Caracas: PROFAL/Nueva Sociedad, 1992.

Molina Duarte, Simon, "Venezuela y el CARICOM: una relación comercial paradójica", EL Universal, Caracas, 11 de diciembre de 1992.

Ochoa Antich, Fernando, "Discurso ante la Cámara Venezolano-Americana", Zeta, Caracas, Nœ908, 29 de julio de 1992.

Ochoa Antich, Fernando, entrevista en El Diario de Caracas, Caracas, 3 de febrero de 1993, p. 31.

Ortiz Ramírez, Eduardo, "Venezuela y Centroamérica: una perspectiva de la integración", Venezuela y la economía internacional, Cuadernos del Postgrado N³, Fondo Editorial Tropylos / Comisión de Estudios de Postgrado, FACES-UCV, Caracas, 1992a.

Ortiz Ramírez, Eduardo, "La política comercial de Venezuela", Colección Estudios Económicos No16, Banco Central de Venezuela, Caracas, $1992 \mathrm{~b}$.

Ortiz Ramírez, Eduardo, "Apertura y comercio en América Latina", Economia Hoy, Caracas, 3 de febrero de 1993, p. 7.

Osorio, Maribel, "EI crecimiento económico es incompatible con un programa de ajuste", Economía Hoy, Caracas, 4 de noviembre de 1992, pp. 16-17. 
Páez, Tomás, Competitividad: ¿Estrategia Nacional?, Caracas: ILDIS/Nueva Sociedad, 1992, 122 pp.

Palma, Pedro, "La economía venezolana en el período 1974-1988", en: Venezuela Contemporánea. Caracas: Fundación Eugenio Mendoza, 1989.

PROMEXPORT, Evaluación de las exportaciones no-tradicionales 1989-1991. Caracas: Oficina de Promoción de Exportaciones, 1992.

Pumphrey, David et al., "Energy Policy in the Western Hemisphere", Working Papers, No195, Washington, Woodrow Wilson Center, 1991.

Purroy, Miguel Ignacio, "Lecciones de 1992", El Diario de Caracas, Caracas, 23 de enero de 1993, p. 17.

Rodríguez Mendoza, Miguel, "Apertura económica e integración en América Latina. La experiencia de Venezuela", en: Serbin, A.; Stabouli, A. et al., La democracia bajo presión: politica y mercado en Venezuela, INVESP/Nueva Sociedad, Caracas, 1993a (en prensa).

Rodríguez Mendoza, Miguel, entrevista en Economía Hoy, Caracas, 1 de febrero de 1993b, pp. 14-15.

Rojas, Laura, "Aspectos económicos de la política exterior de Venezuela", en: Romero, Carlos (ed.), op. cit.

Rojas, Laura, entrevista en Economía Hoy, Caracas, 22 de enero de 1993, p. 15.

Romero, Aníbal, La miseria del populismo. Caracas: Ediciones Centauro, 1987.

Romero, Carlos (ed.), Reforma y politica exterior en Venezuela. Caracas: COPRE/INVESP/Nueva Sociedad.

SELA, La Iniciativa para las Américas en el contexto de las relaciones de América Latina y el Caribe con los Estados Unidos, SP/RC-IA/DT N22, 22-24 de abril, de 1991a.

SELA, "Apertura comercial e integración regional en América Latina. Diagnóstico y escenarios alternativos", ED/17, julio, $1991 \mathrm{~b}$.

Serbin, Andrés, El Caribe: izona de paz?, Caracas: Nueva Sociedad/Comisión Sudamericana de Paz, 1989, 190 pp.

Serbin, Andrés, Caribbean Geopolitics: Toward Security Trough Peace?. Boulder: Lynne Rienner, 1990, 120 pp.

Serbin, Andrés, "Trinidad: un arco iris fragmentado", El Caribe Contemporáneo, México, 1991a.

Serbin, Andres, "Latin America and the Non-Hispanic Caribbean's European Connection", en: Sutton, Paul (ed.), Europe and the Caribbean. Hong Kong: Macmillan, 1991b, pp. 200-221.

Serbin, Andrés, "El Caribe: mitos, realidades y desafíos para el año $2000^{\text {", }}$ en: Serbin, A. y Anthony Bryan (eds.), El Caribe hacia el año 2000. Desafios y opciones. Caracas: INVESP / Nueva Sociedad, 1991c, pp. 13-33. 


\section{A. Serbin / La política exterior de Venezuela y sus ...}

Serbiur, Andrés, "Cooperación pära la paz en el Caribe", en: Seguridau, paz y desarme: propuestas de concertación pacifica en América Látina y et Caribe. Santiago de Chile: CLADDE-FLACSO, pp. 183-195, 1992a.

Serbin, Andrés, "Seguridad ambiental y cooperación regional: paradigmas, presupuestos, percepciones y obstáculos", en: Serbin, $A$. (ed.), Medio ambiente, seguridad y cooperación regional en el Caribe. Caracas: INVESP/Nueva Sociedad, $1992 \mathrm{~b}, \mathrm{pp}$. 9-26.

Serbin, Andrés, "Venezuela y el Grupo de los Tres en el marco de las transformaciones globales y hemisféricas", en: El Grupo de los Tres. Bogotá: FESCOL, 1992 c, pp. 7-23.

Serbin, Andrés, "Venezuela: Reversal or Renewal?", Hemisphere, Miami, vol. 4, N³, Summer, 1992d, pp. 24-27.

Serbin, Audrés, "Las transformaciones globales y hemisféricas y el Grupo de los Tres: alcances y limitaciones de su proyección subregional", en: Serbin, Andrés y Carlos Romero (eds.), El Grupo de los Tres: Evolución y perspectivas, Caracas: INVESP/FESCOL/Nueva Sociedad, 1993a, (por salir).

Serbin, Andrés, "Crónica de un cambio anunciado: el "gran viraje y la política exterior de Venezuela", en: Tulchin, J, et al., Lessons of the Venezuelan Experience, 1993b, (por salir).

Serbin, Andrés y Stambouli, A. "La democracia bajo presión", en: La democracia bajo presión: política y mencado en Venezuela. Caracas: INVESP/Nueva Sociedad, $1993 \mathrm{c}$.

Serbin, Andrés, "Venezuela y el Caribe: un reto persistente?", ms., Caracas, $1993 \mathrm{~d}$.

Silva Michelena, Héctor, entrevista en Economía Hoy, Caracas, 4 de noviembre de 1992 , pp. 16-17.

Sonntag, Heinz y Thais Mangón, Venezuela: 4-F 1992, un análisis sociopolitico. Caracas: Nueva Sociedad, 1992, 110 pp.

Tarre, Maruja, El Diario de Caracas, 10 de febrero de 1993, p. 4.

Toro Hardy, Alfredo, La maldición de Sísifo. 15 años de política externa venezolana. Caracas: Panapo, 1991.

Toro Hardy, El Diario de Caracas, 1993.

Toro Hardy, José, Venezuela: 55 años de política económica 1936-1991. Una utopia keynesiana. Caracas: Panapo, 1992.

Tulchin, Joseph, "La Iniciativa Bush para las Américas",América Latina Hoy, Madrid, N4, julio, 1992, pp. 39-48.

Tulchin, Joseph et al.,Lessons of the Venezuelan Experience, 1993, (por salir). Zambrano, Luis, "Perspectivas macroeconómicas de Venezuela 1992-1996", ponencia en el 1er. Taller sobre Libre Comercio e Impacto Ambiental en Venezuela, Caracas, 8-10 de julio de 1992.

Zambrano, Luis, "Principales problemas y proyectos: sensibilidad al comercio internacional y al control ambiental", ponencia al $2^{\circ}$ Taller sobre 


\section{ESTUDIOS INTERNACIONALES}

Libre Comercio e Impacto Ambiental en Venezuela, Miami, 11-14 de enero de 1993.

Zapata, Juan Gonzalo, "El G-3: punto intermedio entre el Pacto Andino y la Iniciativa para las Américas", Documentos del FESCOL, Bogotá, junio, 1992.

(WR) Weekly Report (Latin American), WR-92-35, September 10, 1992, p. 1. Weill, Roberto A., "Venezuela versus México, Chile y Argentina", El Universal, Caracas, 6 de marzo de 1993, p. 2-2.

(WIC) West Indian Commission, Time for Action, Bridgetown: WIC, 1992. 
A. Serbin / La política exterior de Veniezuela y sus ...

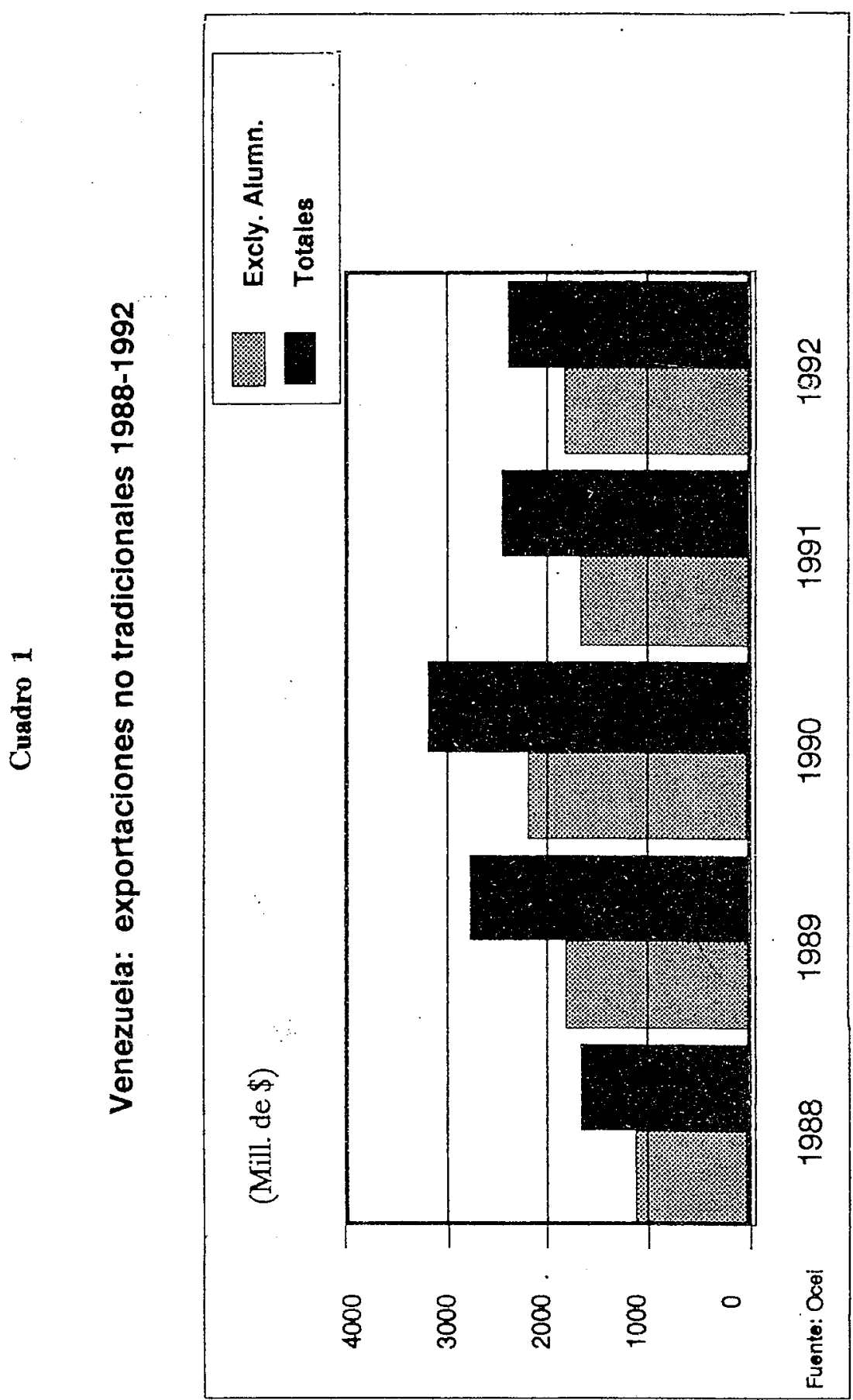

[671] 
ESTUDIOS INTERNACIONALES

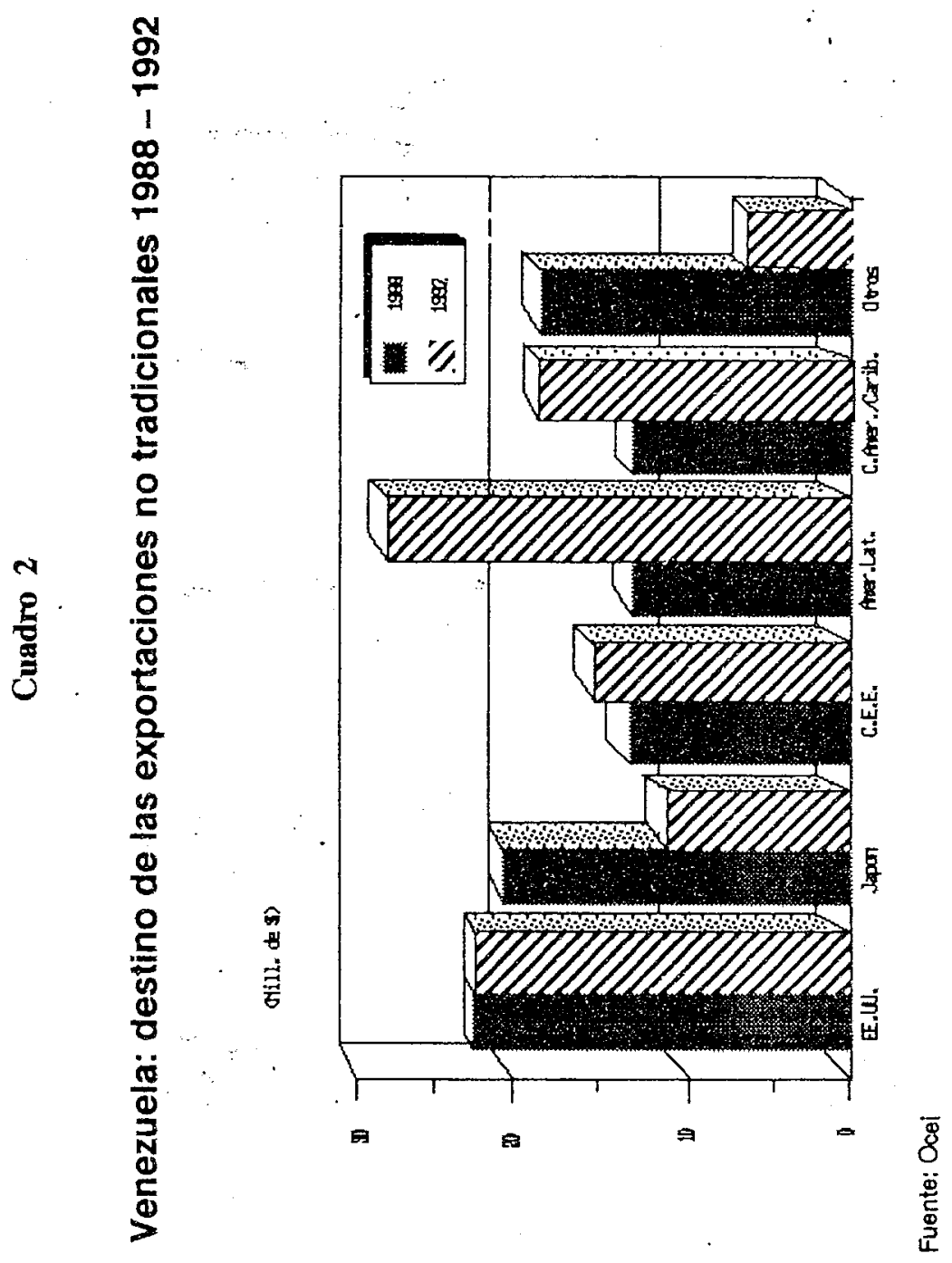


A. Serbin / La polśtica exterior de Venezuela y sus ...
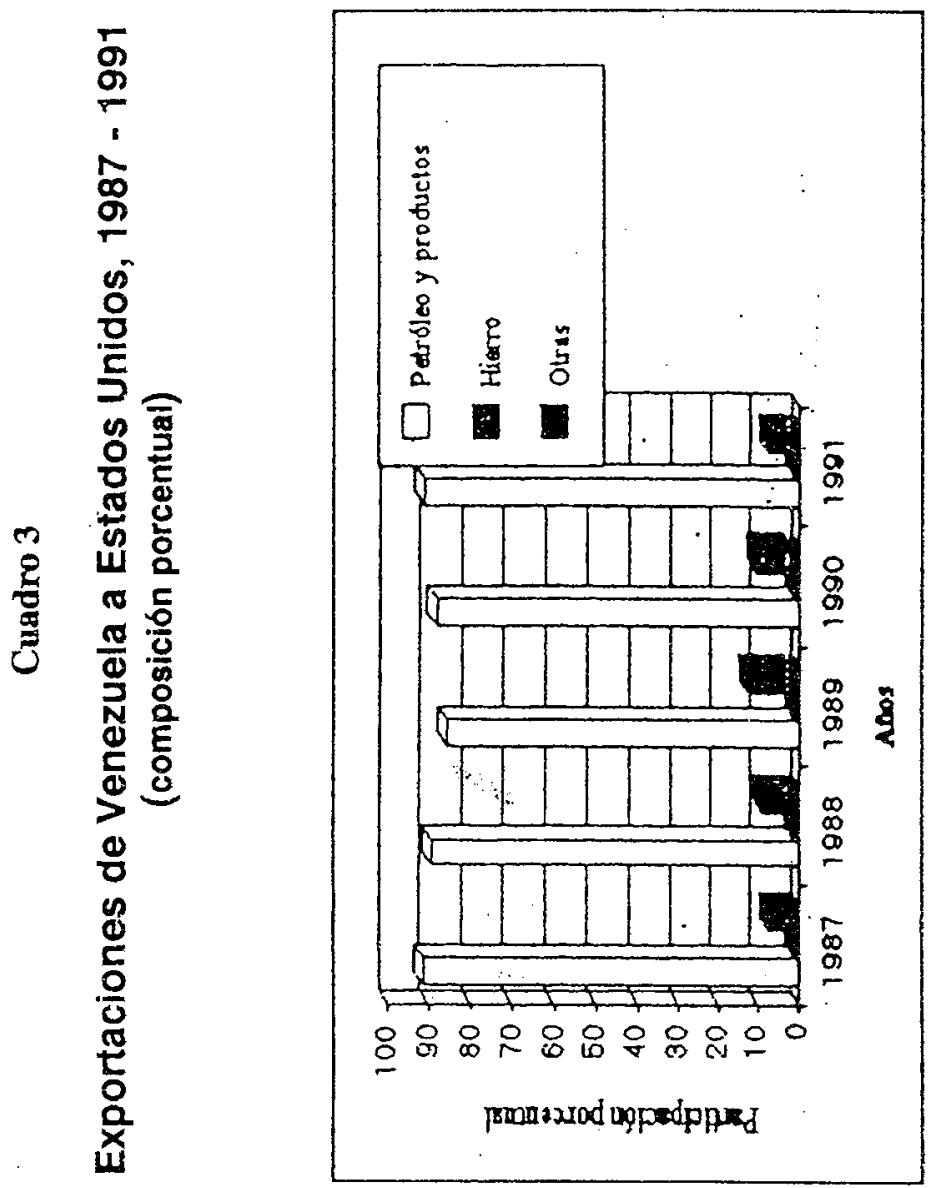
ESTUDIOS INTERNACIONALES

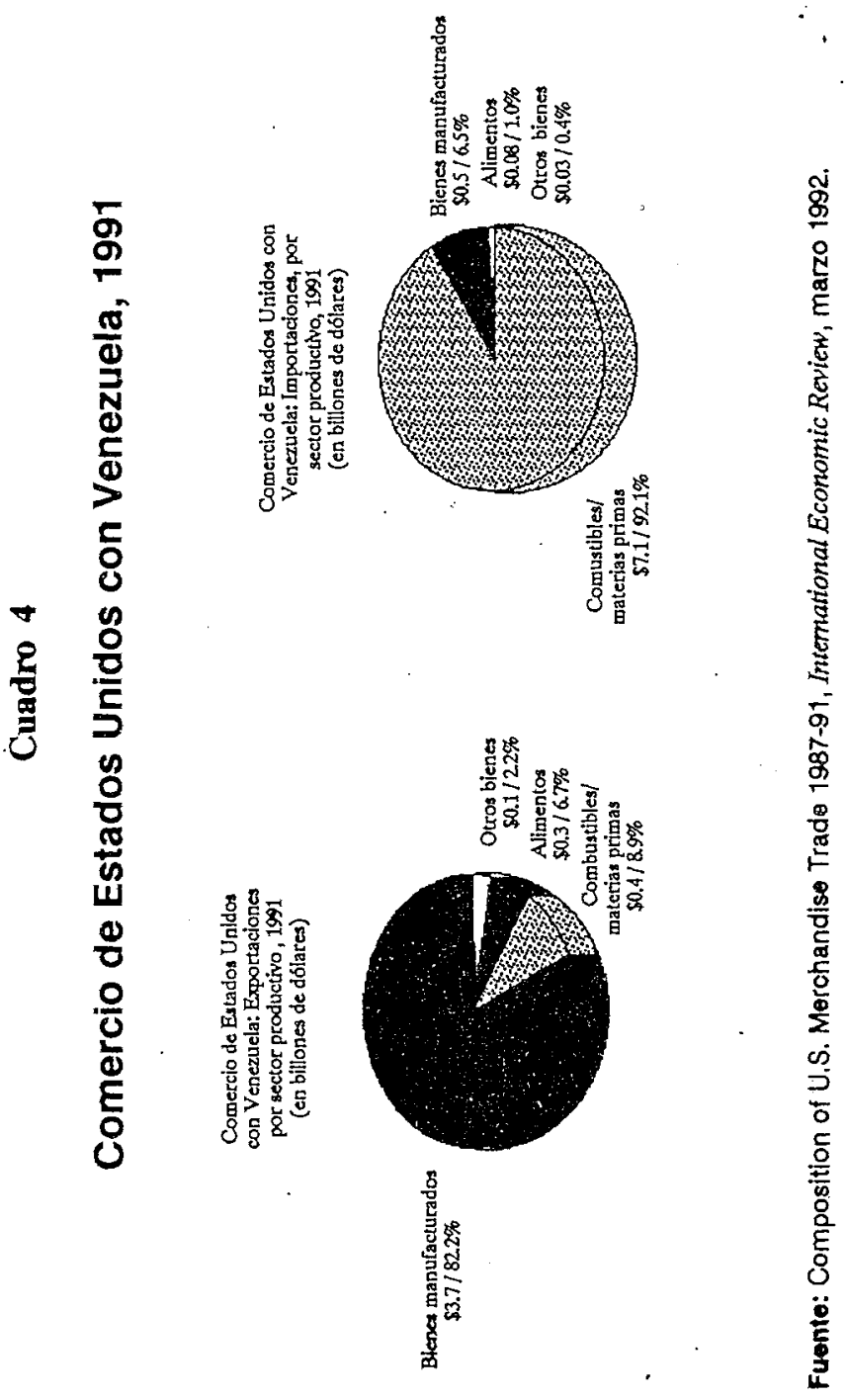


A. Serbin / La poiftica extenior de Venczuela y sus ...

Cuadro 5

Comercio de Estados Unidos con Venezuela: Exportaciones, Importaciones y Balanza Comercial, por Sector Productivo, 1987-91

Comercio de Estados

Unidos con Venezuela.

Alimentos:

exportaciones,

importaciones, y

balanza comerclai,

1987-91

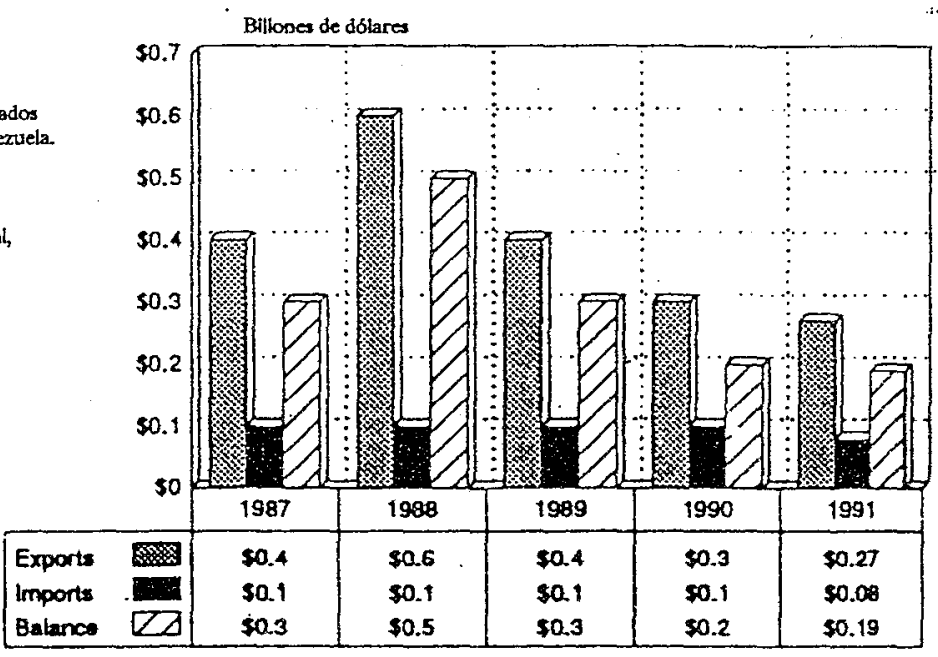

Comercio de Estados

Unidos con Venezuela.

Combrustibles y

Materias primas;

exportaciones.

importaciones, $y$

balanza comercial

1967-91

\begin{tabular}{l}
\hline \\
\end{tabular}


Comercio de Estados Unidos con Venezuela. Bienes

Manufacturados: exportacioses, importaciones, $y$ balanza comercial, 1987-91
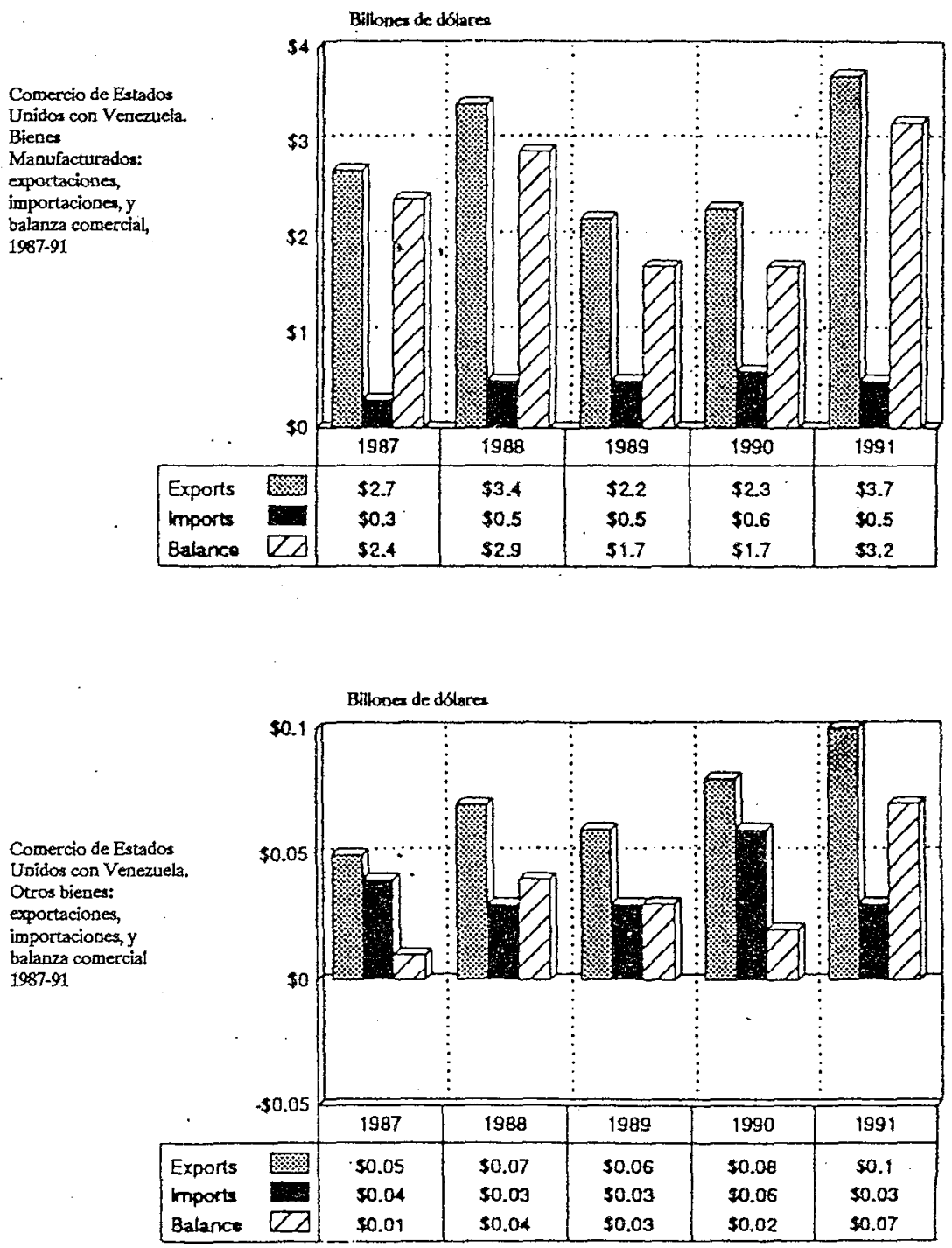

Fuente: U.S. International Trade Commission, SpecialEdition / Chartbook, marzo 1992. 
A. Serbin / La política exterior de Venezuela y sus ...
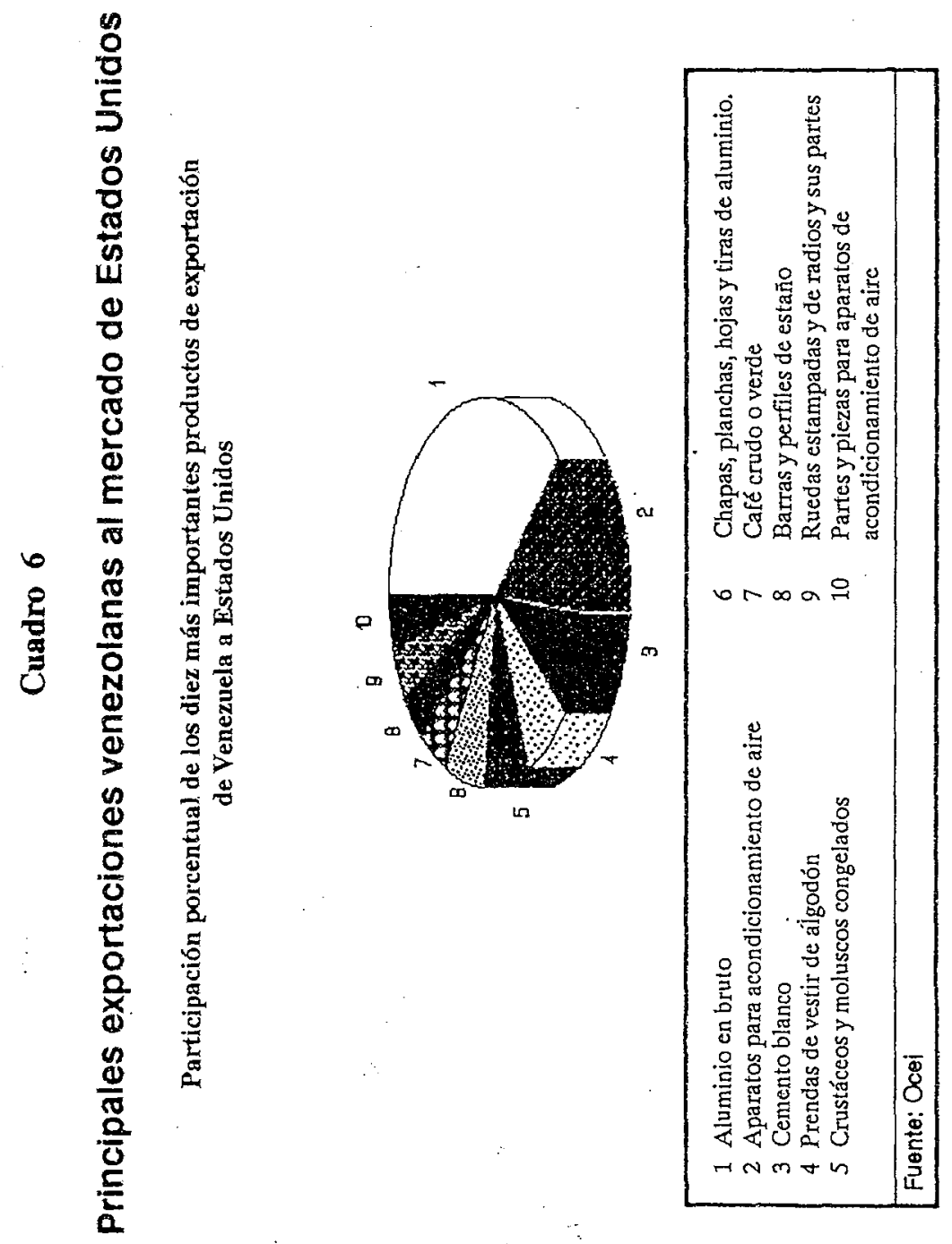


\section{Cuadro 7}
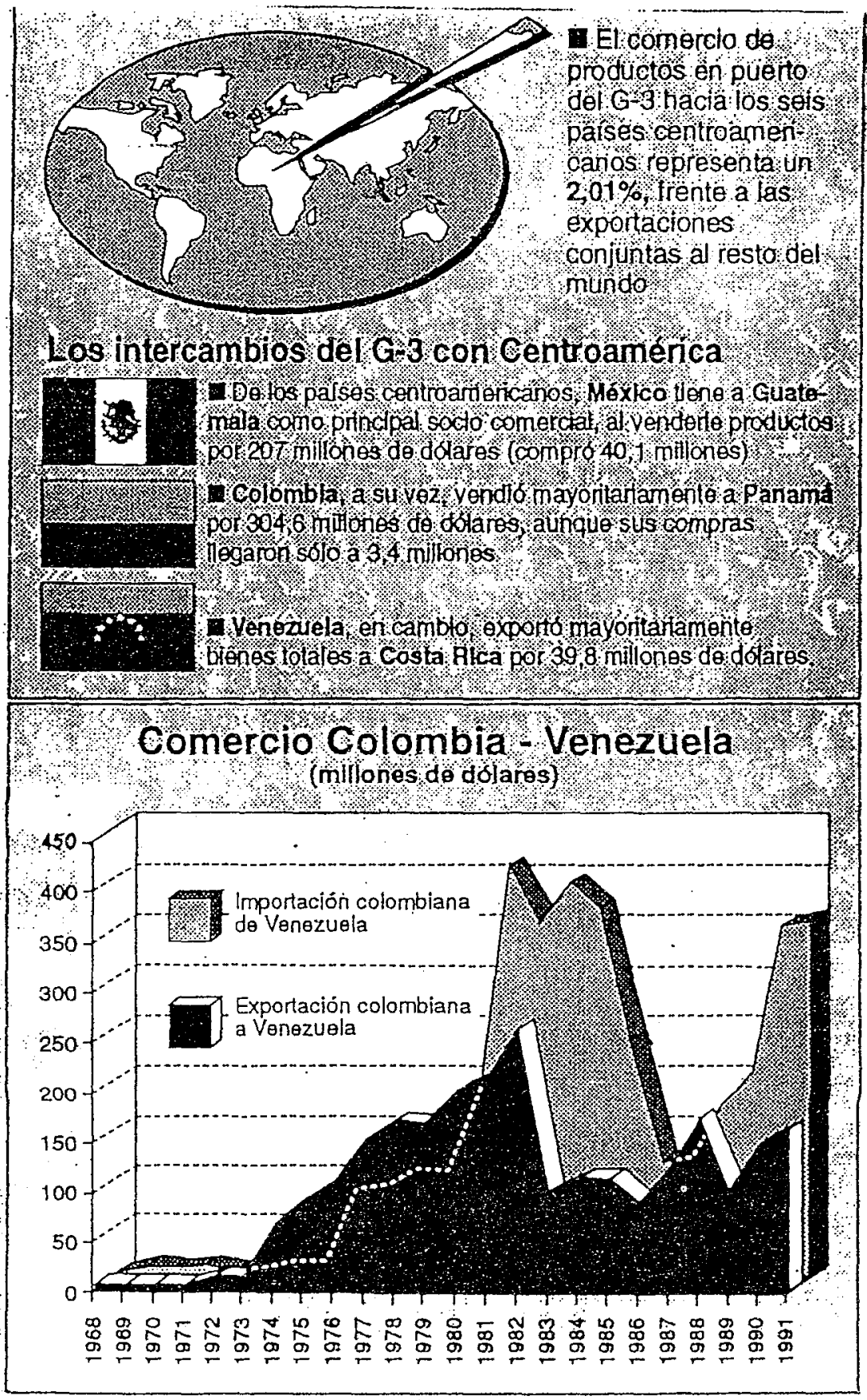
A. Serbin / La política exterior de Venezuela y sus ...

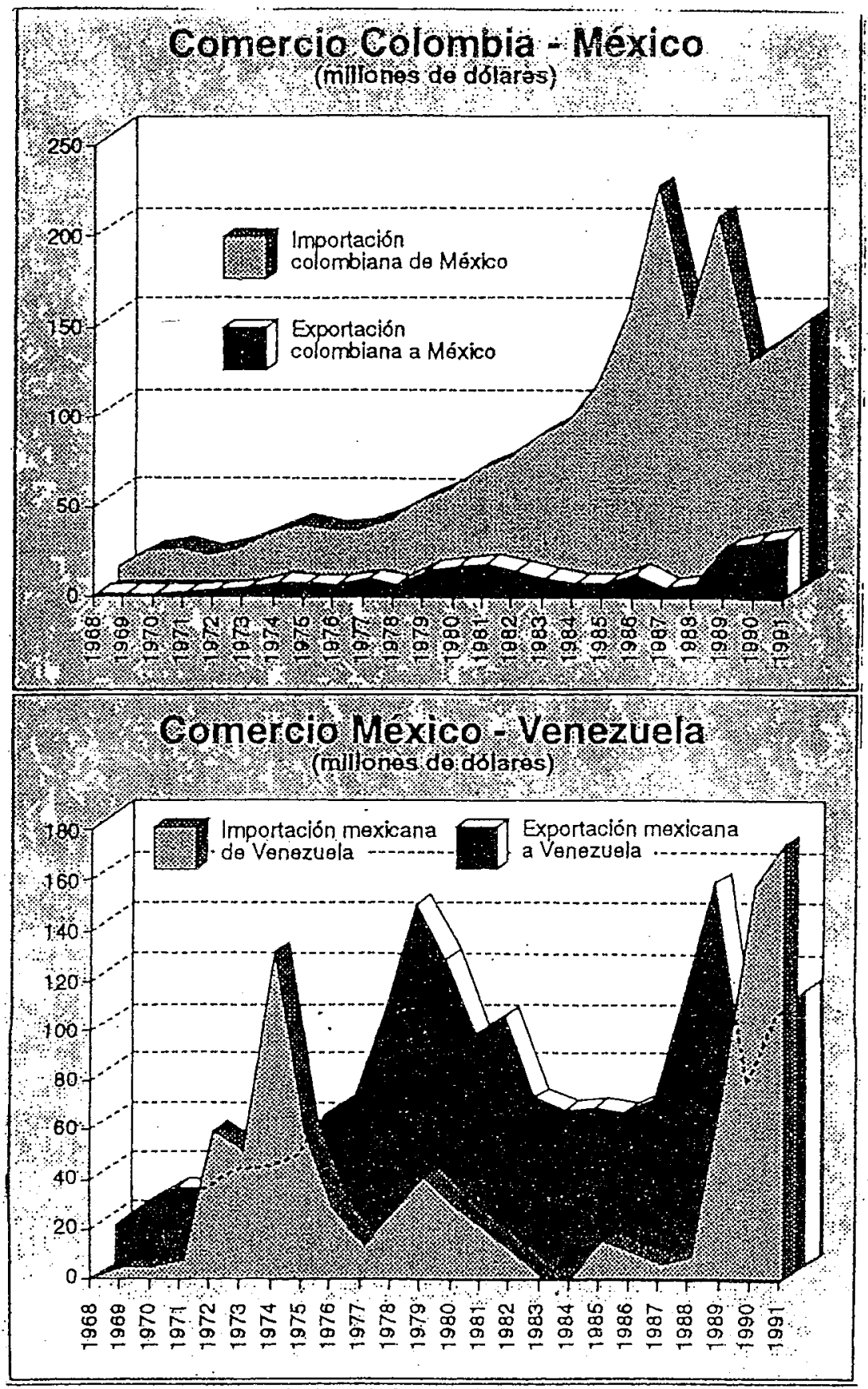

Chras según el Antiarto Estadistico Lalinoamertcano y del cartoe de la Cepal de 199 i 


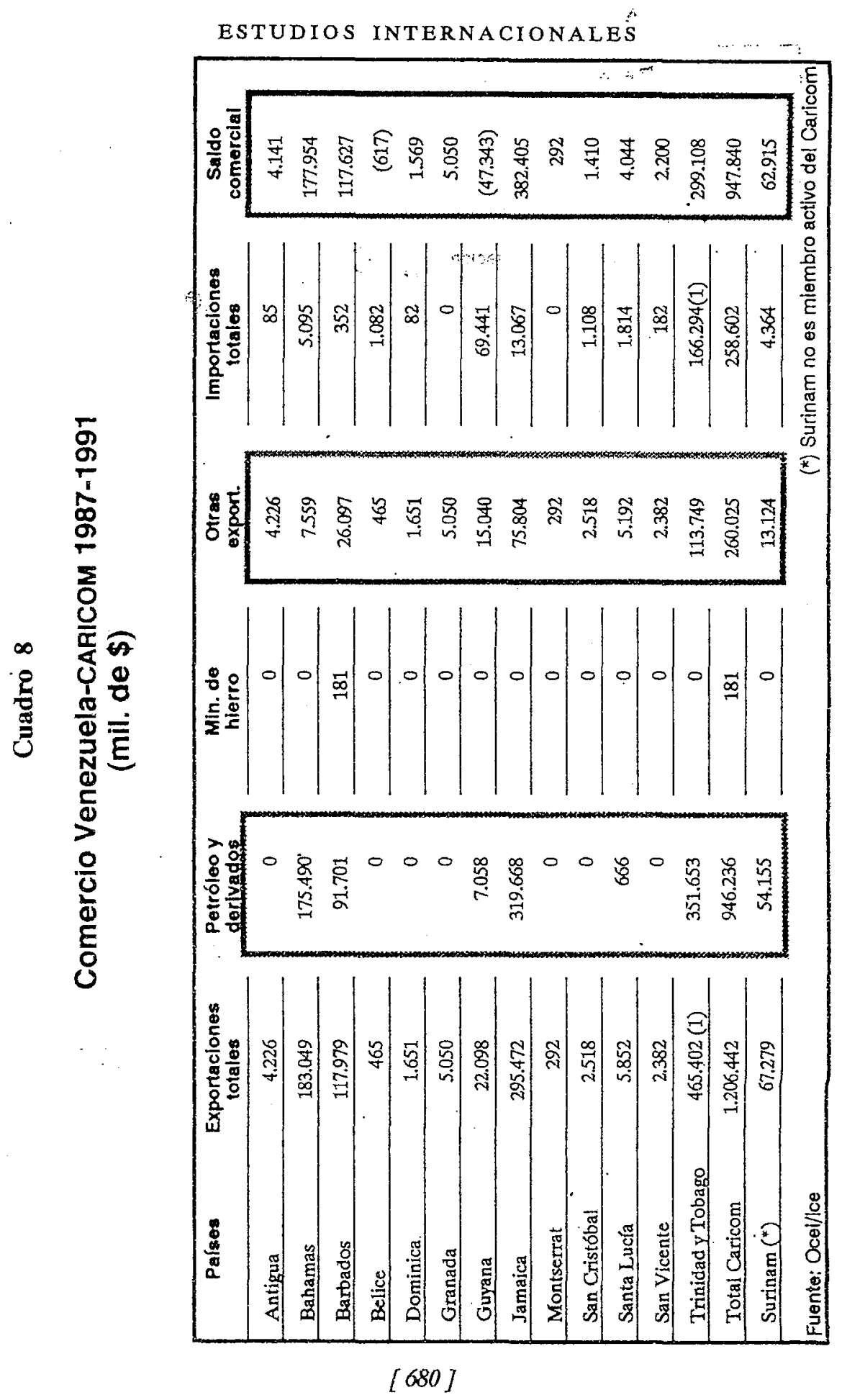

